\title{
Proposta de um procedimento alternativo para avaliar o ofuscamento: uma abordagem temporal da direção da visão
}

\author{
Proposal for an alternative procedure for glare \\ assessment: a new temporal approach of viewing \\ direction
}

\section{Natalia Giraldo Vásquez \\ Fernando Oscar Ruttkay Pereira \\ Leticia Niero Moraes* Maíra Oliveira Pires}

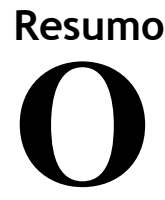
desenvolvidos para quantificar este fenômeno. Os modelos de avaliação de brilho existentes assumem usuários com direções da visão fixas, ignorando o caráter temporal/dinâmico da visão. Neste estudo, um professor foi adotado como sujeito dinâmico para a caracterização das diversas direções da visão. Sendo um trabalho experimental, os procedimentos adotados envolveram o uso de vídeo, um programa para edição de vídeo, imagens HDR e o uso do programa Photolux para o processamento das imagens. Com o valor do DGI obtido para cada direção da visão, a partir de cada posição, em todos os cenários e o tempo que o professor manteve a sua visão para cada direção, foram realizadas duas ponderações pelo tempo de permanência: DGItd (em cada direção) e DGItp (em cada posição), permitindo calcular o índice total para a sala de aula. Os resultados indicaram reduções de até 30\% no DGI total da sala, com relação ao DGI estático. Este estudo reforça a relevância de se incorporar a condição temporal na avaliação do ofuscamento.

Palavras-chaves: Iluminação natural. Ofuscamento. HDR. Direção da visão.

Natalia Giraldo Vásquez

Universidade Federal de Santa Catarina

Florianópolis - SC - Brasil

Fernando Oscar Ruttkay Pereira Universidade Federal de Santa Catarina

Florianópolis - SC - Brasil

Leticia Niero Moraes* Universidade Federal de Santa Catarina Florianópolis - SC - Brasil

Maíra Oliveira Pires Universidade Regional Integrada do Alto Uruguai e das Missões Santo Ângelo - RS - Brasil

Recebido em 01/05/15 Aceito em 24/09/15

in memoriam

\section{Abstract}

Glare can be considered as one of the most complex aspects of the daylighting evaluation process due to its subjective nature and the limitations of $\$$ usual forms of assessment. Although the glare is a subjective response, many indices have been developed to quantify this phenomenon. Existing glare assessment models assume that occupants' view direction fixed on the task and ignore the dynamic nature of vision. This paper presents the impact of the time in the calculation of DGI. A teacher was adopted as a dynamic subject who has several view directions. The procedures adopted included the use of a video camera, software for video editing, HDR images and post processing data through photometric measurement system called Photolux. With DGI data for each direction of view, in each position, in all scenarios and the time in which the teacher looked at each direction, estimated through the video, two weights were held: DGItd (time spent in each direction) and DGItp (time spent in each position) resulting in a total index of the room. The results showed that the total index of the room was lower than those values obtained from Photolux in most cases, reaching reductions of up to $30 \%$ for a given situation. This study reinforces the importance of incorporating the temporal condition in evaluating glare.

Keywords: Daylighting. Glare. HDR. View direction. 


\section{Introdução}

A avaliação do conforto visual possui grande carga de subjetividade, não só pelas preferências dos usuários por certo nível de luz, senão também pelas preferências derivadas do conteúdo visual que o ambiente ou a cena vista possa oferecer. Hopkinson (1972) concluiu que a visão para o exterior é um mediador ou um fator de melhoria para avaliações de brilho. Estas primeiras aproximações à influência do conteúdo visual e à tolerância ao brilho foram constatadas posteriormente por Tuaycharoen e Tregenza (2005, 2007) a partir de comentários de observadores. Nesses estudos, as cenas com uma grande quantidade de informações visuais aumentaram o nível de tolerância em relação ao desconforto por brilho (TUAYCHAROEN; TREGENZA, 2005, 2007). Às evidencias anteriores soma-se o fato da preferência das pessoas pelos ambientes com janelas, não só pelo contato visual com o exterior, mas pelos benefícios devido ao acesso à luz natural (ARIES; AARTS; VAN HOOF, 2015; BENFIELD et al., 2013; KULLER; LINDSTEN, 1992; STEWART, 1981). Assim, ao serem preferidos esses ambientes a probabilidade de ocorrência de ofuscamento, devido às grandes fontes de iluminação, é maior.

Em termos do fenômeno físico, é possível medir as propriedades fotométricas de um ambiente por meio de dispositivos de medição ponto a ponto, através do uso de equipamentos como luxímetros ou luminancímetros. Igualmente, a quantificação do ofuscamento é possível através dos índices existentes (British Glare Index, Daylight Glare Index, CIE Glare Index, Unified Glare Rating, Visual Comfort Probability e Daylight Glare Probability), já que todos eles contêm informações da luminância da fonte, tamanho, localização e adaptação do observador (CLEAR, 2012). O Daylight Glare Probability (DGP) foi proposto a partir de avaliações subjetivas dos usuários correlacionadas com imagens de alta resolução (High Dynamic Range - HDR), em espaços de escritórios iluminados naturalmente (WIENOLD; CHRISTOFFERSEN, 2006), permitindo avaliar fontes tanto grandes quanto pequenas. No entanto, as equações mencionadas são complexas, só se aplicam a uma gama limitada de variáveis, e cada uma avalia o ofuscamento de forma diferente (CLEAR, 2012). A essas questões soma-se o fato de que o brilho varia com a posição do observador, a direção da visão e a adaptabilidade do olho (KLEINDIENST; ANDERSEN, 2009). Entretanto, tais medições e quantificações não conseguem refletir com acuidade "como" e "o que" uma pessoa está vendo, já que esses dados por si só não constituem um mapeamento do campo visual.
Com a evolução digital das fotografias de alta resolução da gama dinâmica ou HDR (DEBEVEC; MALIK, 1997; REINHARD et al., 2005), e sua validação como uma ferramenta de mapeamento de luminâncias (CAI, 2013; INANICI, 2006, 2010, 2013), é possível analisar conjuntos de dados complexos e correlacioná-los com a avaliação da probabilidade de ofuscamento gerada pela transmissão e/ou reflexão luminosa dos sistemas de aberturas na direção do campo visual dos observadores (WIENOLD; CHRISTOFFERSEN, 2006; WIENOLD, 2009).

Uma das principais limitações compartilhadas por todos os índices de brilho conhecidos é que eles ignoram a direção da visão (VD), definida como o lugar para onde dirigimos nosso olhar pela mudança combinada de movimentos dos olhos, cabeça e corpo (CLEAR, 2012). Os modelos de avaliação de brilho existentes assumem que a direção da visão dos ocupantes é fixa e direcionada para a área de tarefa. Uma tentativa de incluir a direção da visão nas avaliações foi proposta por Jakubiec e Reinhart (2011, 2012). O trabalho apresentou um modelo adaptativo de conforto visual a partir de uma "zona adaptativa", permitindo aos usuários mudar a direção da visão em $45^{\circ}$ para cada um dos lados e assim evitar o ofuscamento em um espaço de trabalho. Os resultados desse trabalho evidenciam as diferenças no cálculo do ofuscamento entre os vários índices usados, principalmente na presença de radiação solar direta no interior e o tamanho da fonte; porém, os autores concluem que o DGP oferece resultados mais sólidos (JAKUBIEC; REINHART, 2011, 2012), embora em estudo posterior tenha sido revelado que a ferramenta Evalglare, usada nos estudos de Jakubiec e Reinhart (2011, 2012), apresenta resultados mais confiáveis na avaliação do ofuscamento quando os dados de luminância são inseridos de forma manual (SUK; SCHILER, 2013).

Por outro lado, Van Den Wymelenberg (2014) questiona o uso da simulação para estudar o ofuscamento devido à impossibilidade de reproduzir todos os elementos que existem em uma cena real (como a modelagem dos objetos internos e externos do ambiente a ser avaliado), além de não contar com a avaliação subjetiva dos ocupantes e todas as variáveis pessoais que esse tipo de avaliação envolve. Embora tenham sido realizados grandes avanços no desenvolvimento dos programas de simulação computacional e nas tecnologias usadas para levantamento de dados em tempo real, o autor destaca a dependência que há entre os índices usados para avaliar o ofuscamento 
e a visão, sendo a direção de visão um dos fatores que precisam de maior clareza e diretrizes para ser considerada nessas avaliações (VAN DEN WYMELENBERG, 2014).

Recentemente, têm-se visto o desenvolvimento de estudos com a ferramenta de Eye-Tracking, ou rastreamento da visão, que consiste no mecanismo de um óculos que permite conhecer a direção da visão do usuário e a localização das fontes de ofuscamento segundo o foco da visão (KHANIE $e t$ al., 2013a, 2013b). Khanie et al. (2013a) realizaram um experimento com 23 participantes utilizando a tecnologia eye-tracking para uma melhor compreensão da direção da visão em função de variações de luminosidade. $\mathrm{Na}$ configuração do experimento foram posicionadas duas câmeras para avaliar as variações de distribuição de luminância ao longo da duração de cada ensaio utilizando o mapeamento de luminância com a técnica HDR. Os participantes desenvolveram atividades na tela do computador, atividades de escrita em papel e atendimento ao telefone, todas com foco de visão frontal (KHANIE et al., 2013a, 2013b).

Já os recentes estudos de Kent et al. (2014, 2015) levam em consideração mais uma variável que afeta o brilho percebido e a avaliação do ofuscamento: a hora do dia. Embora o estudo tenha sido realizado em ambientes controlados e com iluminação artificial, os resultados indicaram que a hora do dia tem influência na avaliação do ofuscamento e na tolerância a fontes de luz mais brilhantes. Os autores sugerem que se aprofundem estudos em espaços iluminados naturalmente, assim como no levantamento das variáveis pessoais de forma mais precisa (KENT et al., 2014, 2015).

As ferramentas para o levantamento das condições fotométricas, os programas de simulação computacional e os índices para a avaliação do ofuscamento têm sido aprimorados e ajustados continuamente para melhorar a qualidade dos resultados das pesquisas, porém, em termos das questões subjetivas, ainda são necessários mais estudos. Neste trabalho foi testado, de forma experimental, um método para avaliar a sensação do ofuscamento em atividades dinâmicas através de dados obtidos de forma estática pelo uso de imagens HDR. Durante o desenvolvimento do experimento foi percebido que o tempo de permanência do observador em uma posição e olhando para uma direção específica pode ser mais uma variável que impacta na avaliação do ofuscamento geral de um ambiente. Nesta pesquisa, uma primeira aproximação e inclusão da questão da temporalidade foi ensaiada.

\section{Método}

A avaliação do ofuscamento tem sido amplamente estudada a partir de um cenário cujo observador realiza uma tarefa que requer condições mais estáticas. No entanto, pesquisas que consideram atividades mais dinâmicas, nas quais o observador possua maior variação no campo visual por causa do movimento, não são comuns. Neste estudo, a avaliação do ofuscamento foi realizada considerando o campo visual de um professor em sala de aula enquanto ministra o conteúdo de uma disciplina. Como complemento a esta análise, o campo visual de alunos sentados em cada um dos quatro cantos da sala de aula também foi considerado.

O levantamento dos dados envolveu a identificação da localização do professor dentro da sala de aula (principais lugares de permanência enquanto fazia sua apresentação); identificação das principais direções da visão a partir de cada um dos lugares de maior permanência; estimativa do tempo de permanência em cada uma dessas posições e tempo dedicado às diferentes direções identificadas; e aquisição de imagens HDR em cada posição e para cada direção sob três posições das cortinas, usadas para regular a iluminação natural.

\section{Características do ambiente}

Com o intuito de realizar um estudo do campo visual que considerasse condições normais da atividade, foi realizado um levantamento prévio para conhecer a direção da visão de um grupo de alunos e de um professor, em uma aula teórica do Curso de Arquitetura e Urbanismo da Universidade Federal de Santa Catarina. Para este estudo foram considerados os dois tipos de usuários desse espaço:
(a) o professor (observador 1); e
(b) os alunos (observadores 2, 3, 4 e 5).

O local no qual foi realizado o levantamento dos dados foi uma sala de aula do Departamento de Arquitetura e Urbanismo da Universidade Federal de Santa Catarina. O ambiente possui duas fachadas externas orientadas a sudoeste e noroeste, com janelas em ambas as faces. As janelas apresentam proteções solares verticais e horizontais, e internamente são utilizadas cortinas de cor escura. A porta de acesso ao ambiente é de vidro e está localizada no corredor do prédio. Cabe salientar que o vidro superior da porta foi coberto pelos próprios usuários com papel branco. As características arquitetônicas do espaço de avaliação em termos de número e distribuição das 
aberturas estão apresentadas na Figura 1. A malha traçada na planta representa a disposição das carteiras. Os pontos em laranja indicam a localização dos estudantes presentes na sala durante o período de filmagem da aula, usada para caracterizar as posições e direções da visão do professor no estudo.

Figura 1 - Posições dos observadores, direções da visão e características gerais da sala de aula LOCAL E CARACTERÍSTICAS DAS AVALIAÇÕES Data: 21-11-2014 Horário: 14h39min até 16h00min POSIÇÕES DO OBSERVADOR 1 E DIREÇÕES DA VISÃO

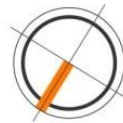

\section{Observador 1}

Atividade: Ministrar aula

Altura olhos: 1,70m

Duração video analisado: $1833 \mathrm{~s}$ POSIÇÃO 1

POSIÇÃO 2

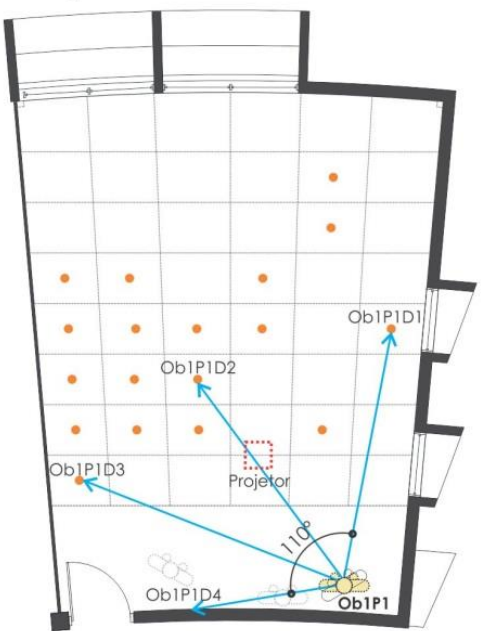

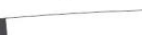

*Nesta posição o observador esteve na frente da luz do projetor.

\section{POSIÇÃO DOS OBSERVADORES} 2,3,4 E 5 E DIREÇÃO DA VISÃO

Atividade: Assistir aula Altura olhos sentado: $1,20 \mathrm{~m}$ Situações definidas

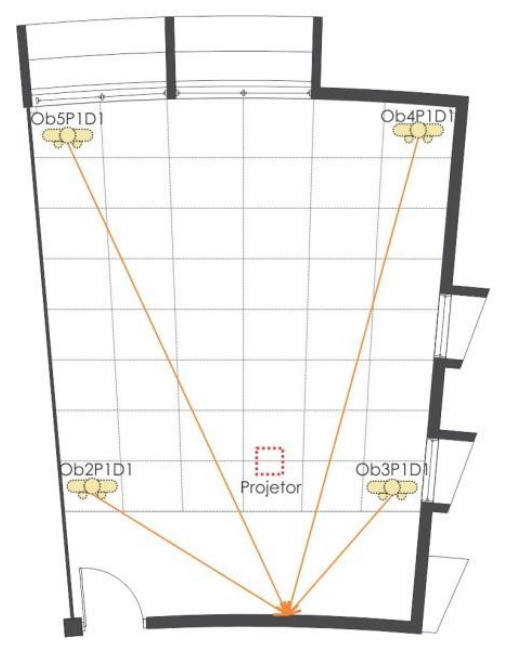

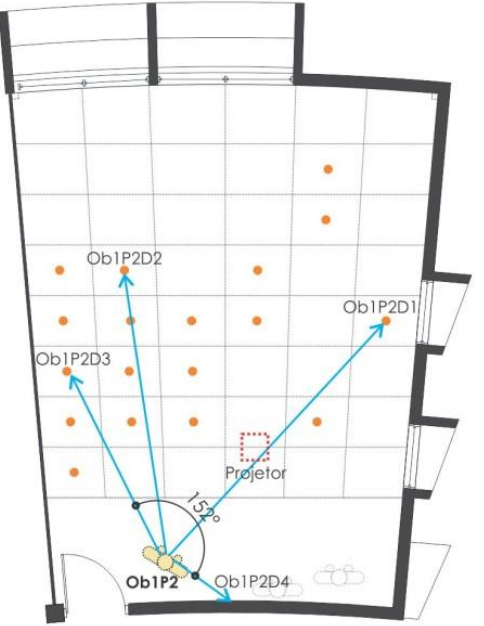
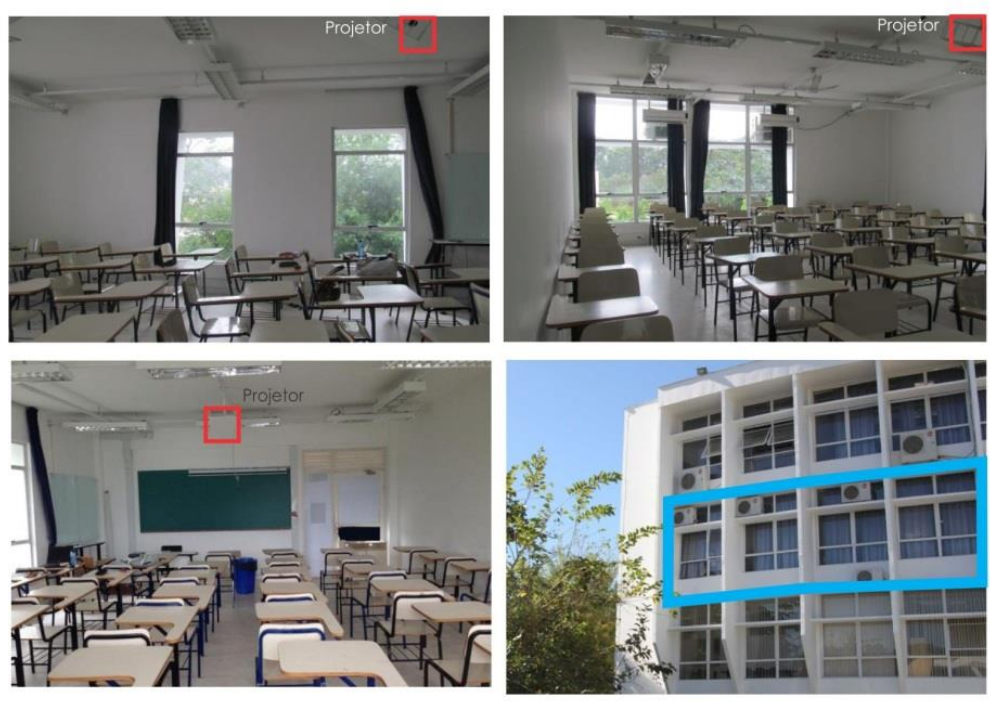

POSIÇÃO 3*

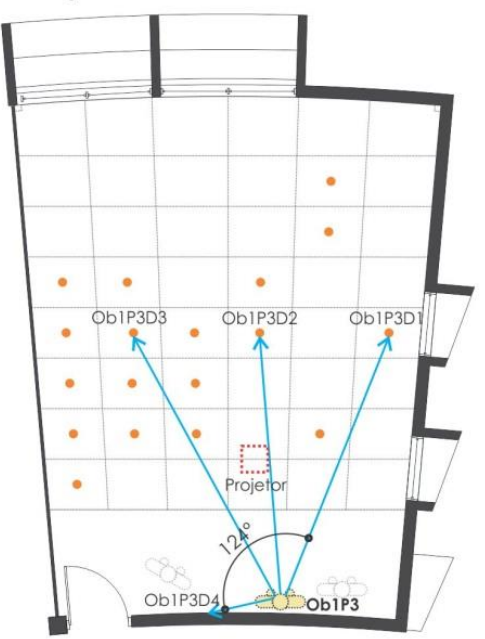

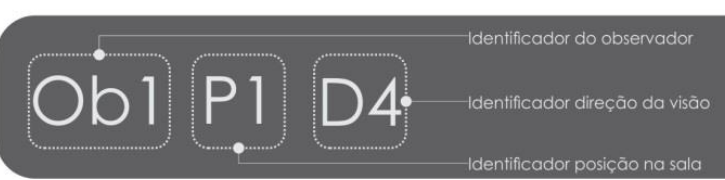

146 Vásquez, N. G.; Pereira, F. O. R.; Moraes, L. N.; Pires, M. O. 
Além das variáveis pessoais apresentadas, foram considerados três cenários da luz natural (lâmpadas apagadas), conforme o uso das cortinas:

(c) cortinas fechadas;

(d) cortinas parcialmente fechadas; e

(e) cortinas abertas.

As avaliações foram realizadas no dia 21 de novembro de 2014, durante a tarde, das 14h39min às 16 h00min, já que nesse horário a sala de aula estava disponível para as medições. As avaliações foram realizadas sob uma condição de céu parcialmente encoberto, havendo radiação solar direta sobre algumas das superfícies internas a partir das 15h30min nos cenários 2 e 3 . Sendo o uso de projeção de imagens por meio de projetor uma prática recorrente em aula, essa característica de uso foi considerada durante a aquisição das imagens. A Tabela 1 apresenta as modificações nas variáveis e o total de avaliações realizadas.

\section{Levantamento e identificação da direção da visão}

Para o caso dos alunos foram avaliadas quatro posições dentro da sala de aula (onde estão localizadas as carteiras, em cada um dos quatro cantos), considerando que nesses pontos de avaliação o observador estaria sentado. Em um vídeo realizado durante $30 \mathrm{~min}$ de aula foi possível identificar que a direção da visão predominante no período no qual os alunos assistem a aulas teóricas é direcionada para a superfície na qual são projetadas as informações (quadro-preto ou tela).

Já no caso do observador 1, tanto a posição na sala de aula quanto a direção da visão apresentaram mais variações. $\mathrm{O}$ vídeo permitiu reconhecer os percursos realizados pelo professor e a direção de sua visão enquanto falava. Durante os $30 \mathrm{~min}$ de filmagem foram identificadas três posições principais do professor, cada uma com quatro direções predominantes da visão (D1, D2, D3 e D4). Essas direções estiveram relacionadas com a localização dos alunos dentro da sala de aula. A edição do vídeo permitiu identificar também a permanência do observador em cada posição e o número de vezes que olhou para cada uma dessas direções. A Tabela 2 apresenta as estatísticas de número de vezes em que o observador olhou para cada direção da visão, a partir de cada uma das três posições dentro da sala de aula. Na Figura 1 foram apresentadas as posições de cada observador e as direções da visão.

A Figura 2 apresenta as imagens levantadas a partir de cada posição do observador 1. As características do conteúdo visual mudaram conforme as variações na direção da visão. Nas direções D1, D2 e D3 houve maior abrangência do ambiente geral da sala de aula. Na direção D4 o campo visual é ocupado principalmente pela parede que continha a superfície de projeção. Nas direções D1 até D3, a partir da posição 3, é possível identificar o brilho do projetor com maior intensidade.

\section{Cálculo do tempo de permanência em cada posição e para cada direção da visão}

A partir da duração total do vídeo realizado, de $1.833 \mathrm{~s}$, e através de um software de edição de vídeo (Movie Maker) foram separados por segmentos os momentos nos quais o observador 1 esteve em cada uma das três posições identificadas. Posteriormente, esses segmentos foram agrupados por posição, permitindo conhecer o tempo de permanência do observador em cada uma delas. A Tabela 3 apresenta os dados de tempo estimados a partir dos vídeos.

Tabela 1 - Variáveis usadas no estudo e número de avaliações realizadas

\begin{tabular}{|c|c|c|c|c|c|c|c|}
\hline $\begin{array}{c}\mathbf{N}^{\circ} \\
\text { CENARIOS } \\
\end{array}$ & CÉ́U & PROJETOR & OBSERVADOR & $\begin{array}{c}\text { POSIÇÕES } \\
\text { OBSERVADOR } \\
\end{array}$ & $\begin{array}{c}\text { DIREÇÕES } \\
\text { VISÃ̃ } \\
\end{array}$ & \begin{tabular}{|l|} 
SUBTOTAL \\
SITUAÇÕES \\
\end{tabular} & TOTAL \\
\hline \multirow{5}{*}{3} & \multirow{5}{*}{1} & \multirow{5}{*}{ Ligado } & 1 & 3 & 4 & 36 & \multirow{5}{*}{48} \\
\hline & & & 2 & \multirow{4}{*}{1} & \multirow{4}{*}{1} & 3 & \\
\hline & & & 3 & & & 3 & \\
\hline & & & 4 & & & 3 & \\
\hline & & & 5 & & & 3 & \\
\hline
\end{tabular}

Tabela 2 - Número de vezes que o observador 1 olhou para cada direção da visão a partir das três posições

\begin{tabular}{|c|c|c|c|c|c|c|c|c|c|c|c|}
\hline \multicolumn{4}{|c|}{ POSIÇÃO 1} & \multicolumn{4}{|c|}{ POSIÇÃO 2} & \multicolumn{4}{|c|}{ POSIÇÃO 3} \\
\hline$\overline{\text { D1 }}$ & $\mathrm{D} 2$ & D3 & D4 & $\overline{\mathrm{D} 1}$ & D2 & $\overline{\mathrm{D} 3}$ & D4 & D1 & $\overline{\mathrm{D} 2}$ & D3 & $\overline{\mathrm{D} 4}$ \\
\hline 43 & 81 & 34 & 49 & 18 & 12 & 2 & 16 & 10 & 8 & 4 & 3 \\
\hline
\end{tabular}


Figura 2 - Características do conteúdo visual de cada direção da visão a partir de cada posição
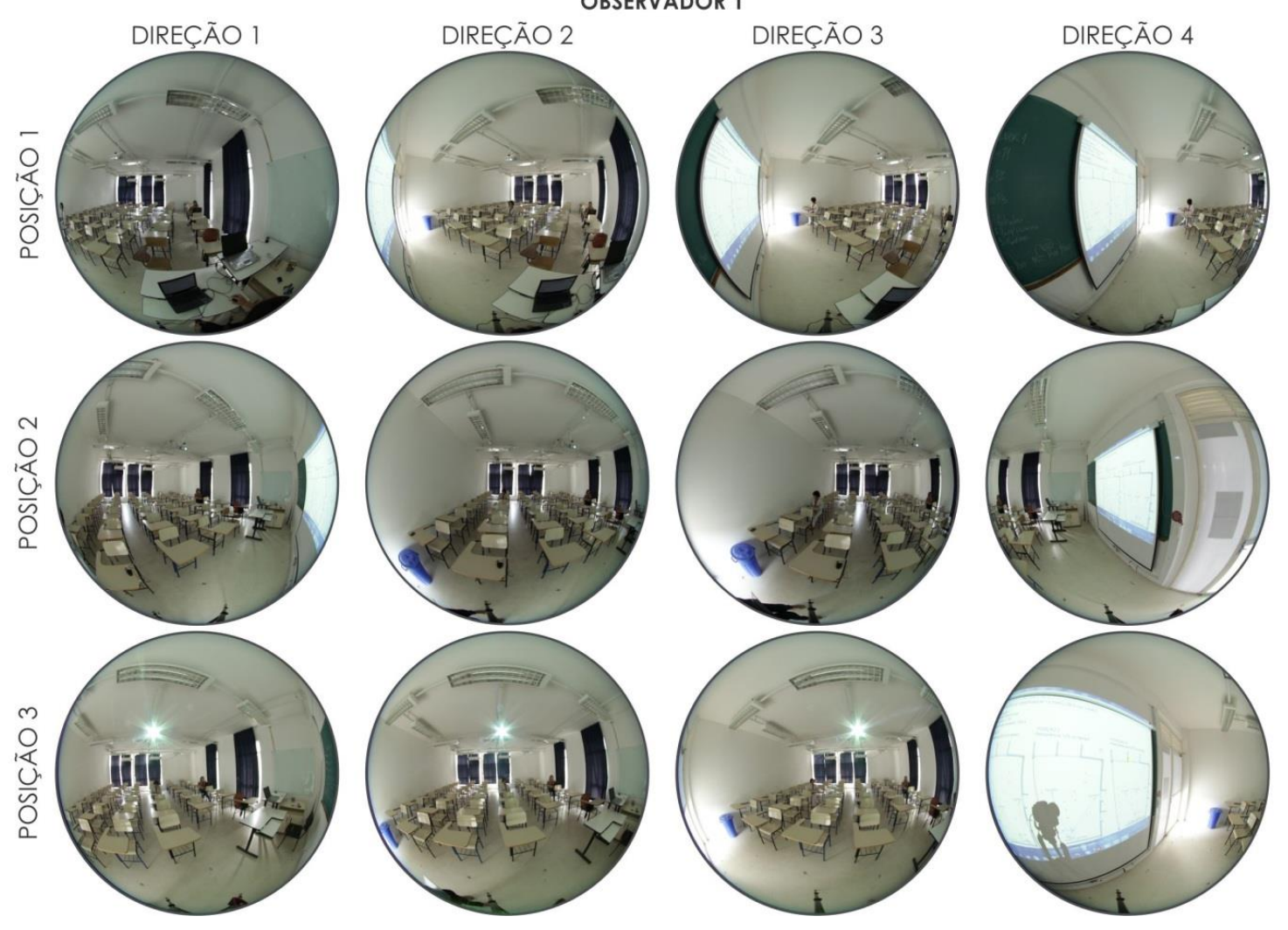

Tabela 3 - Cálculo do tempo de permanência em cada posição e tempo olhando para cada direção da visão

\begin{tabular}{|c|c|c|c|c|c|c|c|c|c|c|c|c|}
\hline & \multicolumn{4}{|c|}{ POSIÇÃO 1} & \multicolumn{4}{|c|}{ POSIÇÃO 2} & \multicolumn{4}{|c|}{ POSIÇÃO 3} \\
\hline Direção da visão & D1 & $\mathrm{D} 2$ & D3 & D4 & D1 & $\mathrm{D} 2$ & D3 & D4 & D1 & D2 & D3 & D4 \\
\hline $\begin{array}{l}\text { Número de vezes que } \\
\text { olhou para cada } \\
\text { direção da visão }\end{array}$ & 43 & 81 & 34 & 49 & 18 & 12 & 2 & 16 & 10 & 8 & 4 & 3 \\
\hline $\begin{array}{l}\text { Tempo em segundos } \\
\text { em que olhou para } \\
\text { cada direção (s) }\end{array}$ & 291 & 549 & 230 & 332 & 83 & 55 & 9 & 73 & 46 & 37 & 18 & 14 \\
\hline $\begin{array}{l}\text { Percentagem do tempo } \\
(\%)\end{array}$ & 21 & 39 & 16 & 24 & 38 & 25 & 4 & 33 & 40 & 32 & 16 & 12 \\
\hline
\end{tabular}

O tempo restante foi considerado como tempo gasto em deslocamento do observador para mudar de posição.

\section{Aquisição de imagens High Dynamic Range}

Devido à capacidade das imagens HDR de gravar toda a gama de luz que chega a um ponto no espaço, elas contêm informações sobre forma, cor e intensidade das fontes de luz direta, assim como cor e distribuição da luz indireta de superfícies no resto da cena (REINHARD et al., 2005). Essa técnica utiliza fotografias tiradas com vários graus de exposição para capturar a variação de luminâncias que uma cena pode apresentar. Para qualquer câmera fotográfica que tenha capacidade de fotografar com múltiplas exposições, a função de resposta da câmera pode ser conhecida e usada para fundir a sequência de fotos numa única imagem HDR.

Com o intuito de manter as condições da atividade de forma natural, as fotografias usadas neste estudo foram realizadas no ambiente da sala de aula, sem as atividades rotineiras. Quatro alunos do Programa de Pós-Graduação em Arquitetura e Urbanismo e do Programa de Pós-Graduação em Engenharia Civil ajudaram no levantamento das

148 Vásquez, N. G.; Pereira, F. O. R.; Moraes, L. N.; Pires, M. O. 
fotografias para identificar as direções da visão do professor.

Para a obtenção das imagens em HDR foi utilizada uma câmera fotográfica digital com lente olho de peixe Modelo Canon EOS 60D. Essas imagens foram inseridas no programa Photolux, que simplifica o processamento das fotografias, permitindo a geração de mapas de luminâncias e medições ponto a ponto dos valores de luminância na imagem HDR. Para cada avaliação (ver Tabela 1) foram levantadas sete fotografias, com configurações de abertura e tempo de exposição recomendadas pelo manual do programa Photolux, conforme a Tabela 4. Para este estudo 336 fotos foram necessárias para gerar os mapas de luminâncias de cada avaliação.

Para evitar erros nas imagens devido ao movimento do equipamento ao serem reguladas as características de abertura e tempo de exposição foi utilizado o programa Smartshooter, que possibilita a aquisição de imagens através do uso de um computador.

O programa Photolux possibilita a obtenção de três índices para a avaliação de ofuscamento: o Unified Glare Rating (UGR), o Visual Comfort Probability (VCP) e o Daylight Glare Index (DGI). No entanto, como os dois primeiros índices são limitados por não considerarem a presença de grandes fontes de brilho (como uma janela), neste trabalho adotou-se o índice DGI.

\section{Ponderação dos valores de DGI pelo tempo}

Com os dados do DGI obtidos para cada direção da visão, a partir de cada posição do observador, e o tempo de permanência do observador em cada uma dessas posições, foram realizadas duas ponderações, gerando, assim, dois resultados diferentes. A primeira ponderação, pelo tempo dedicado a olhar cada direção, corresponde ao $D G I_{\mathrm{td}}$, e a segunda ponderação, pelo tempo de permanência em cada posição, corresponde ao $D G I_{\text {tp. }}$.

\section{$D G I_{\text {tempo em cada direção }}$ ou $D G I_{\text {td }}$}

Pelo fato de que em cada posição foram enxergados diferentes pontos dentro da sala de aula, foi realizado um cálculo do DGI que considerasse o tempo em que a visão esteve com o foco em cada direção, para assim obter um valor de DGI para o ângulo sólido conformado pelo movimento total da cabeça. Esse valor, denominado nesta pesquisa como $D G I_{\mathrm{td}}$, é a média ponderada do DGI obtido através do Photolux pelo tempo em segundos em que o observador 1 olhou para cada direção, conforme a Eq. 1. Assim, para cada posição do observador e em cada um dos cenários foi calculado o $D G I_{\mathrm{td}}$.

$D G I_{t d}=$

$\left(D G I_{\text {photoluxd } 1} * \% t_{d 1}\right)+\left(D G I_{\text {photoluxd } 2} *\right.$

$\left.\% t_{d 2}\right) \ldots+\left(D G I_{\text {photoluxdn }} * \% t_{d n}\right)$

Média ponderada do $D G I_{\text {photolux }}$ e a percentagem do tempo olhado para cada direção

Onde:

n: número de direções da visão a partir de cada posição;

$t_{d n}$ : percentagem do tempo em que o observador olhou para cada direção; e

DGI $I_{\text {Photolux dn }}$ : Daylight Glare Index obtido pelo Photolux para cada direção.

$D G I_{\text {total posição }}$ ou $D G I_{\text {tp }}$ e $D G I_{\text {total da sala }}$

Este índice corresponde ao valor do DGI em cada posição e é calculado a partir da ponderação do $D G I_{\text {td }}$ e o tempo total em cada posição (Equação 2).

$D G I_{\text {total posição }}=D G I_{t d} * \% t_{p}$

Eq. 2

Procedimento de cálculo do DGI em cada posição

Onde:

$D G I_{t d}: D G I$ total em cada direção; e

$t_{p}$ : percentagem do tempo em que o observador permaneceu em cada posição.

Com estes dados ponderados foi possível a obtenção de um valor de DGI total para a sala em cada cenário, abrangendo todas as direções da visão do observador 1 durante o período analisado, conforme a Eq. 3.

$D G I_{\text {total sala }}=D G I_{t p_{1}}+D G I_{t p_{2}} \ldots+D G I_{t p_{n}}$ Eq. 2

Cálculo do DGI total da sala de aula

Onde:

$D G I_{t p n}: D G I$ total em cada uma das posições estudadas.

O resultado obtido através dessas duas ponderações introduziu a condição dinâmica no cálculo do índice de ofuscamento. Os dados obtidos foram comparados com os valores de DGI obtidos diretamente do Photolux para verificar o impacto da inclusão do tempo no cálculo deste índice. 
Tabela 4 - Configurações de aberturas e tempo de exposição recomendadas pelo Manual do Photolux

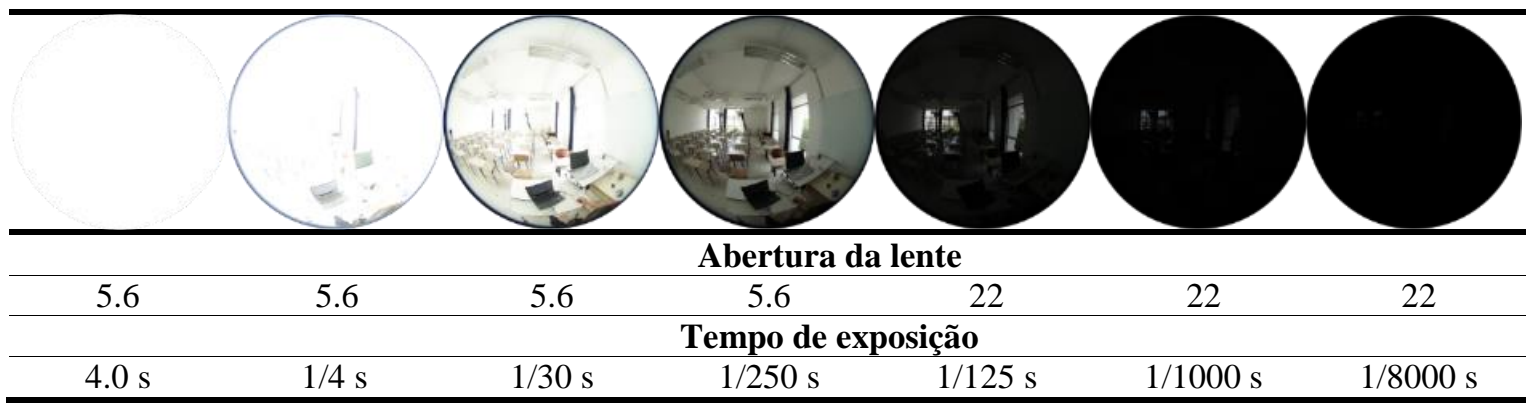

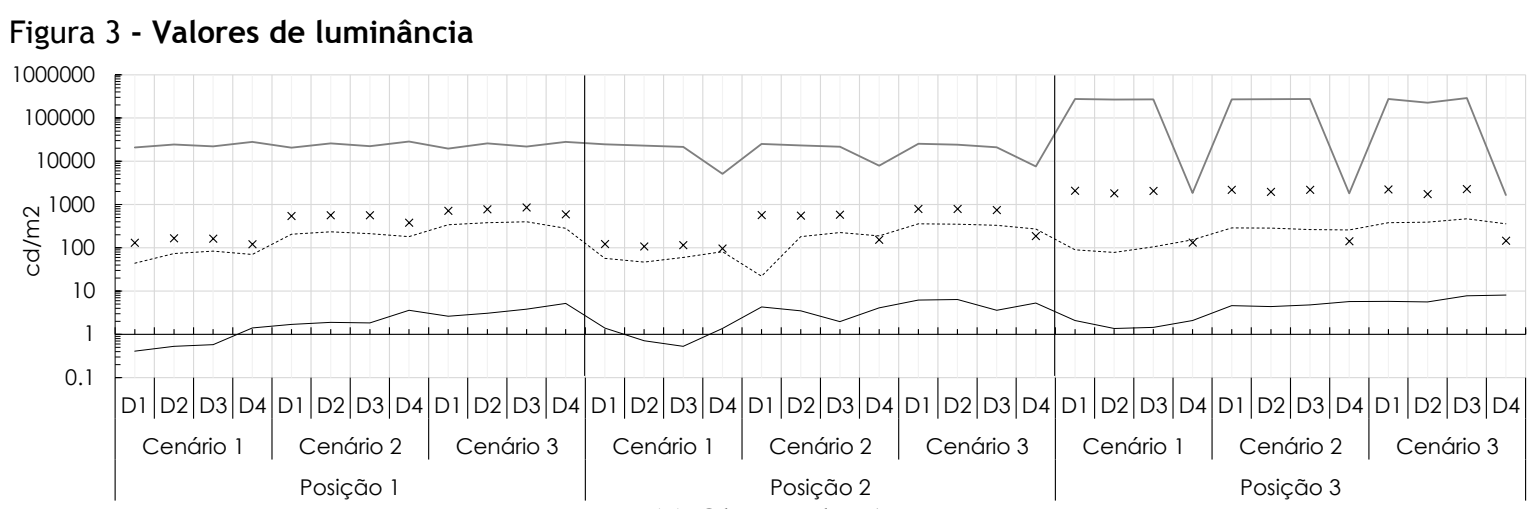

(a) Observador 1

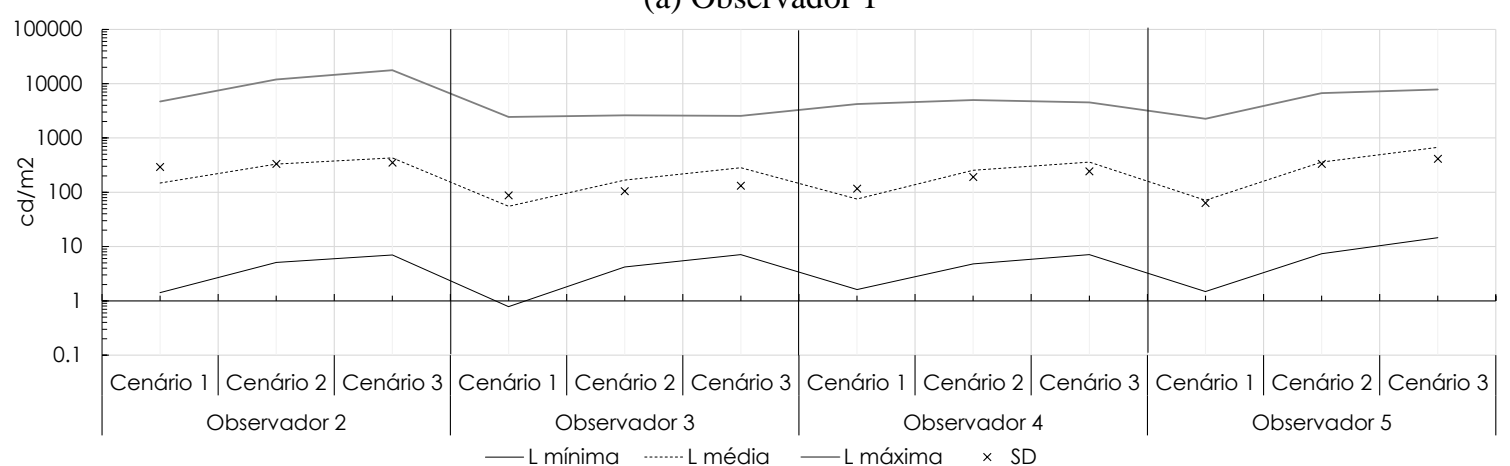

(b) Observadores 2 a 5

\section{Resultados}

\section{Distribuição de luminâncias no campo visual}

$\mathrm{Na}$ Figura 3 são apresentados os valores de luminância máxima, média, mínima $\left(\mathrm{cd} / \mathrm{m}^{2}\right)$ da cena enxergada pelo observador 1 . Na posição 1 os valores máximos da luminância (linha cinza) apresentam certa homogeneidade, mesmo quando nenhuma fonte de luz foi vista, como na direção D4. Nas posições 2 e 3 é possível identificar com maior clareza a influência da direção da visão quando há uma fonte de luz pontual no campo visual. Na direção D4 dessas posições o valor máximo apresenta queda, pois a luz do projetor não faz parte do campo visual. No caso da posição 3 a queda foi maior devido ao posicionamento da fonte de luz pontual, o projetor, no campo visual em relação às outras posições, assim como devido a seu tamanho aparente (maior).

A Figura $3 b$ apresenta os valores de luminância máxima, média, mínima $\left(\mathrm{cd} / \mathrm{m}^{2}\right)$ da cena enxergada pelos observadores 2 a 5 . Neste estudo os quatro cantos da sala de aula foram os pontos a partir dos quais foram realizadas as avaliações desses observadores, correspondendo com a possível localização de alunos dentro do ambiente.

Ao analisar os dados de DGI do campo visual e valores de luminância do observador 3 é possível identificar o impacto da posição da fonte de luz no campo visual na avaliação do ofuscamento. A partir da posição deste observador foram registrados os maiores valores do DGI, porém os valores de luminância máxima corresponderam à 
posição 2. A proximidade da fonte mais brilhante (neste caso, a parte inferior da porta) com a área de visão central faz com que a distância seja a variável de maior impacto na estimativa do DGI.

Para avaliar a distribuição das luminâncias no campo visual e identificar a influência da posição das fontes de ofuscamento no cálculo obtido foi utilizada uma máscara que representa o campo visual sobre os mapas produzidos no Photolux.

O campo de visão binocular está delimitado por um ângulo sólido de aproximadamente $120^{\circ}$ a $140^{\circ}$ e pode ser dividido em três zonas (Figuras 4 e 5) com diferentes características: a visão central, o ergorama e o panorama. No centro delimitado por um ângulo sólido de $1^{\circ}$ se encontra a área de visão central que fornece a maior acuidade visual. A segunda zona chamada de ergorama está delimitada por um ângulo sólido de $60^{\circ}$, permitindo a percepção da profundidade e a discriminação cromática. Finalmente o panorama é a zona que completa o campo visual. Nessa zona os objetos são dificilmente identificáveis se não estão em movimento (BAKER; STEEMERS, 2002; PANERO; ZELNIK, 2006). Pelas características das atividades analisadas, em vez de analisar o ângulo sólido da visão central $\left(1^{\circ}\right)$, foi adotado um ângulo sólido de $10^{\circ}$.

\section{Figura 4 - Mapas de luminância mais superposição do campo visual na direção da visão 1 para o observador 1 nos três cenários}

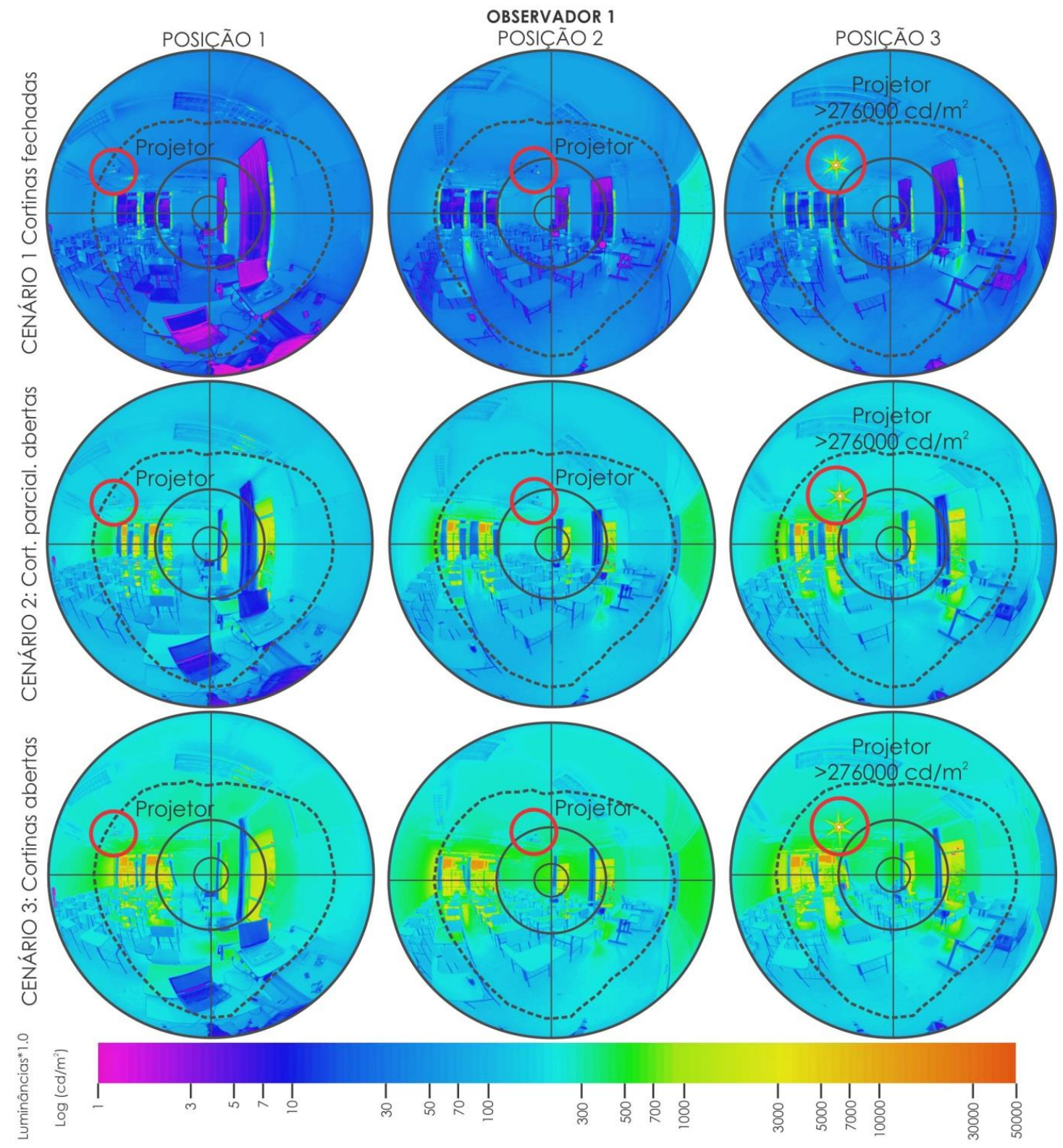


Figura 5 - Mapas de luminância mais superposição do campo visual na direção da visão 1 para os observadores 2 a 5 no cenário 1

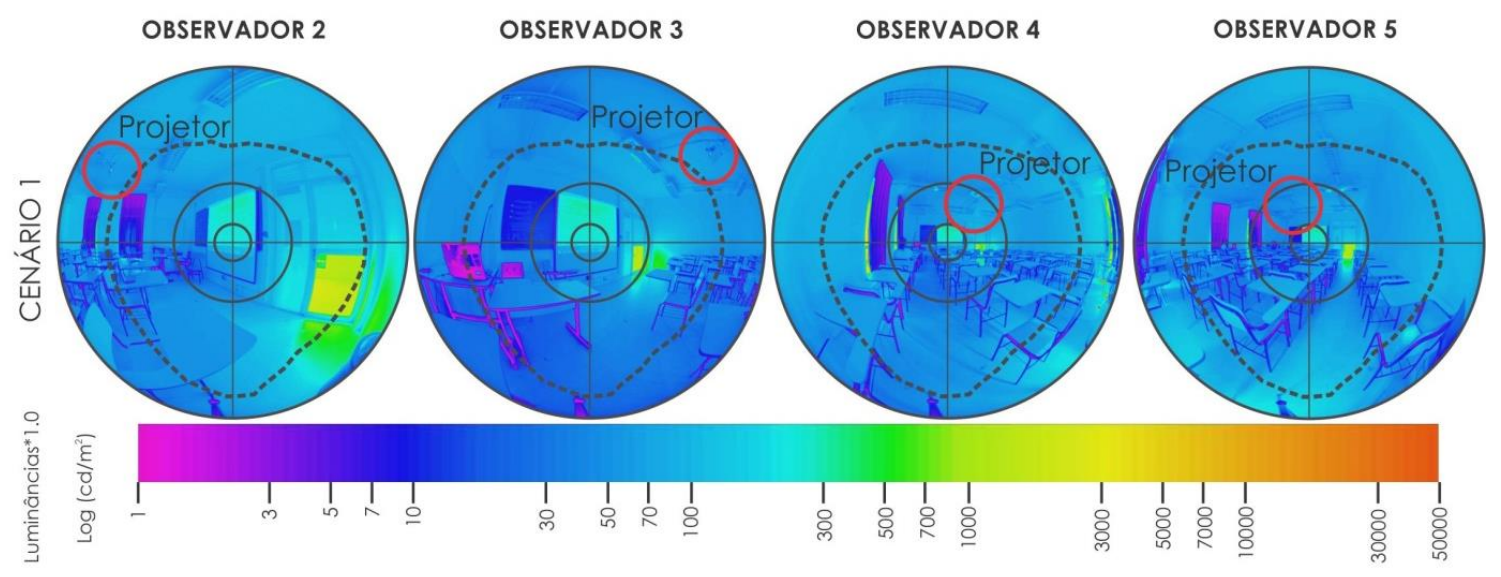

$\mathrm{Na}$ Figura 4 são apresentados os mapas de luminâncias gerados pelo Photolux para as três posições do observador 1 , na direção da visão 1 . Nas imagens é possível identificar que, para o caso da posição 3, a fonte luminosa do projetor está localizada na região do panorama e com valores de luminância superiores a $270.000 \mathrm{~cd} / \mathrm{m}^{2}$, o que justifica os maiores valores de DGI encontrados para esta posição.

Os mapas de luminância correspondentes aos observadores $2,3,4$ e 5 sob as condições do cenário 1 (Figura 4) evidenciam o efeito gerado pela parte inferior da porta, já que em todos os cenários esta é a maior área de fonte de luz. No caso do observador 3 essa configuração resulta mais desconfortável devido a sua localização (centro de campo visual), induzindo a maiores valores de DGI.

\section{DGI obtido através do software Photolux}

O conjunto de sete imagens obtido para cada posição e direção da visão foi inserido no programa Photolux, que permitiu a geração dos mapas de luminância e a obtenção do índice DGI para cada configuração de cena visual. A Figura 6a apresenta os valores de DGI para cada uma das quatro direções da visão e a partir das três posições do observador 1. A Figura $6 \mathrm{~b}$ apresenta os valores do DGI para a única direção da visão avaliada para os observadores 2 a 5 . As sensações de ofuscamento, segundo o valor do DGI, foram incluídas nos gráficos. A linha azul indica que o ofuscamento é "imperceptível", e a linha vermelha corresponde a uma sensação de ofuscamento “intolerável". As sensações "aceitável" e “desconfortável” correspondem à linha preta e à linha tracejada respectivamente.
No caso dos observadores 2, 3, 4 e 5, os valores levantados a partir de suas localizações dentro da sala de aula estiveram dentro da faixa "imperceptível"/“desconfortável" para os três cenários avaliados. No caso do observador 1 , as diferentes posições dentro da sala de aula, assim como as distintas direções da visão em cada uma das posições, geraram maiores mudanças nos valores do DGI. Esses registros de DGI, em algumas situações, ultrapassaram o limite que indica uma sensação "intolerável” de ofuscamento.

A diferença entre o valor de DGI levantado e o valor de DGI que provocaria uma sensação de ofuscamento "imperceptível" é apresentada na Figura 7a. A Figura $7 \mathrm{~b}$ apresenta a diferença em relação ao valor que representa uma sensação de ofuscamento "aceitável".

Tomando como valor de referência de DGI aquele que causa uma sensação de ofuscamento "imperceptível" (DGI=16), os resultados indicam, sob todos os cenários e para todos os observadores, que nas condições avaliadas haveria presença de ofuscamento para os usuários do ambiente, sejam os alunos ou o professor. As variadas posições e direções da visão do observador 1 ocasionaram as maiores diferenças. A média dessas diferenças foi de $62 \%$ na posição 1 e de $61 \%$ na posição 2 . Na posição 3 deste observador houve aumento da diferença $(\overline{\mathrm{X}}=92 \%)$ devido aos maiores valores registrados no cenário 1 (cortinas fechadas), ocasionados pela presença da luz do projetor no campo visual. Na situação estática representada pelos alunos, os observadores 2 e 3 tiveram as maiores variações $(\overline{\mathrm{X}}=31 \%$ e $\overline{\mathrm{X}}=48 \%$ ) (Figura $7 \mathrm{a})$.

Com relação ao valor de DGI que representa uma sensação "aceitável" (DGI=20) algumas situações apresentaram diferenças negativas, indicando uma avaliação do ofuscamento entre "aceitável" e “imperceptível”. Contudo, o comportamento em

152 Vásquez, N. G.; Pereira, F. O. R.; Moraes, L. N.; Pires, M. O. 
ambas as comparações é similar. Os observadores 2, 3, 4 e 5 apresentam as menores diferenças $(\overline{\mathrm{X}}=5 \%, \overline{\mathrm{X}}=18 \%, \overline{\mathrm{X}}=-4 \%, \overline{\mathrm{X}}=3 \%$ respectivamente), sendo o observador 4 , sob o cenário 2 , o usuário que teria menor sensação do ofuscamento. No caso do observador 1 as condições de seu ambiente visual ainda estiveram fora dos valores necessários para ter uma avaliação do ofuscamento "aceitável", excetuando a direção 4 na posição 1 , sob o cenário 3 , na qual o valor de DGI foi de 16,3. Nas posições 1 e 2 a média das diferenças foi de $29 \%$ em ambas as posições. $\mathrm{Na}$ posição 3 a média foi de $54 \%$.

Figura 6 - Valores de DGI obtidos através do Photolux (a) a partir das três posições do observador 1 e nas quatro direções da visão (D1 até D4); e (b) a partir das posições dos observadores 2 a 5

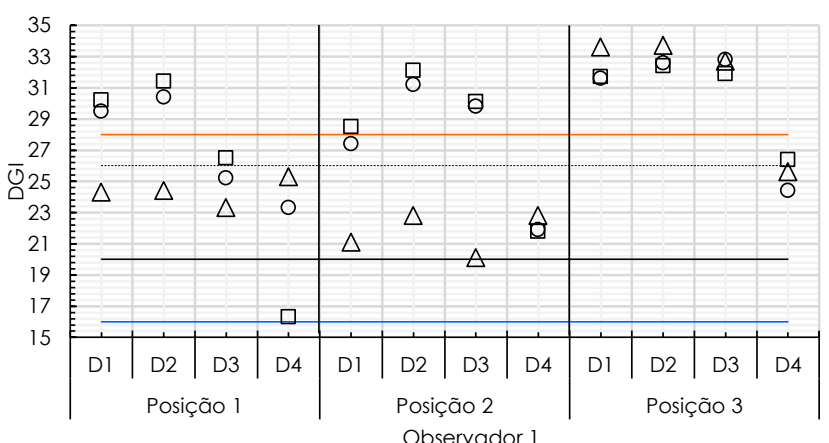

(a)

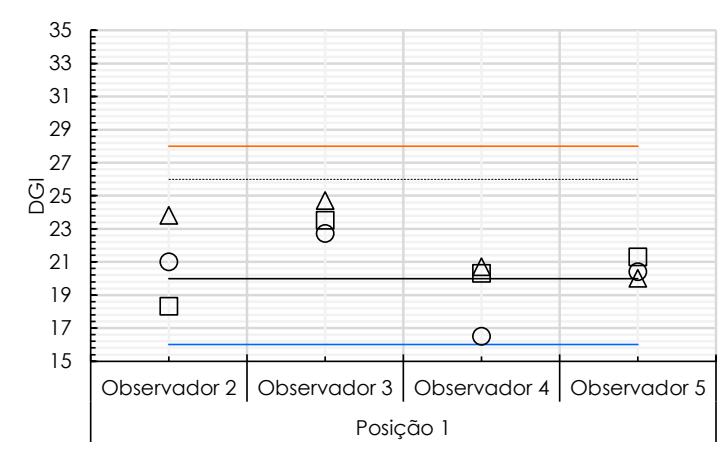

(b)

$\triangle$ Cenário 1 C Cenário $2 \square$ Cenário 3 -DGl imperceptível —DGl intolerável —DGl aceitável …...DGI desconfortável

Figura 7 - (a) Diferença percentual entre o DGIPhotolux e o DGI "imperceptível”; e (b) diferença percentual entre o DGIPhotolux e o DGI "aceitável”

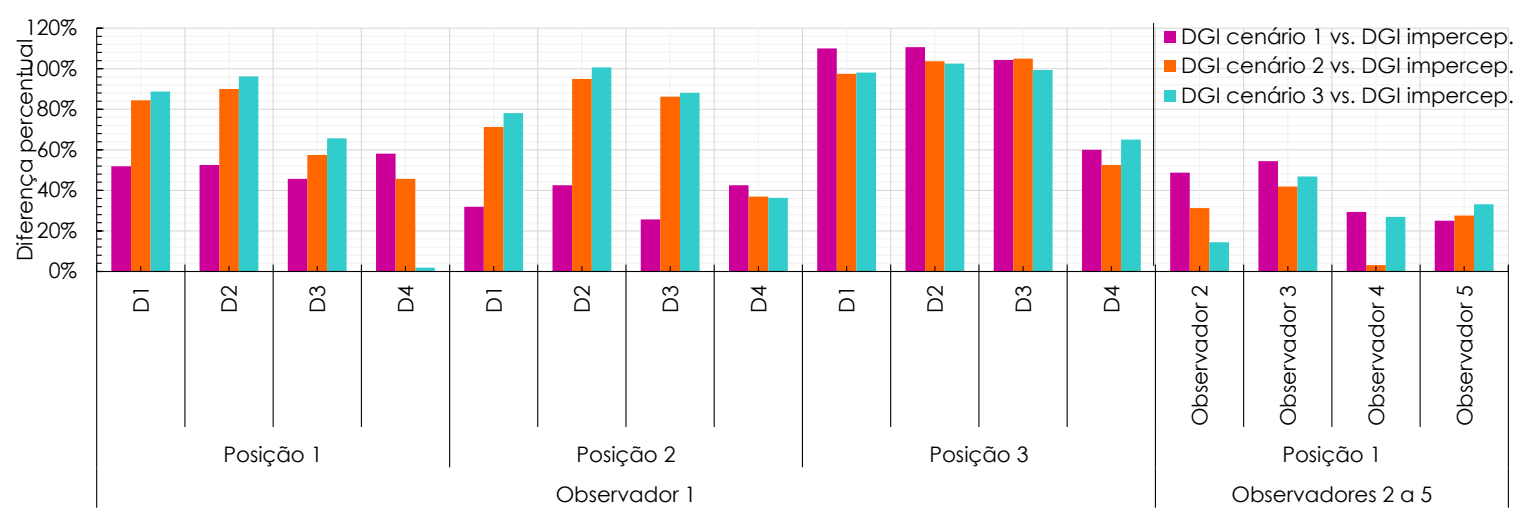

(a)

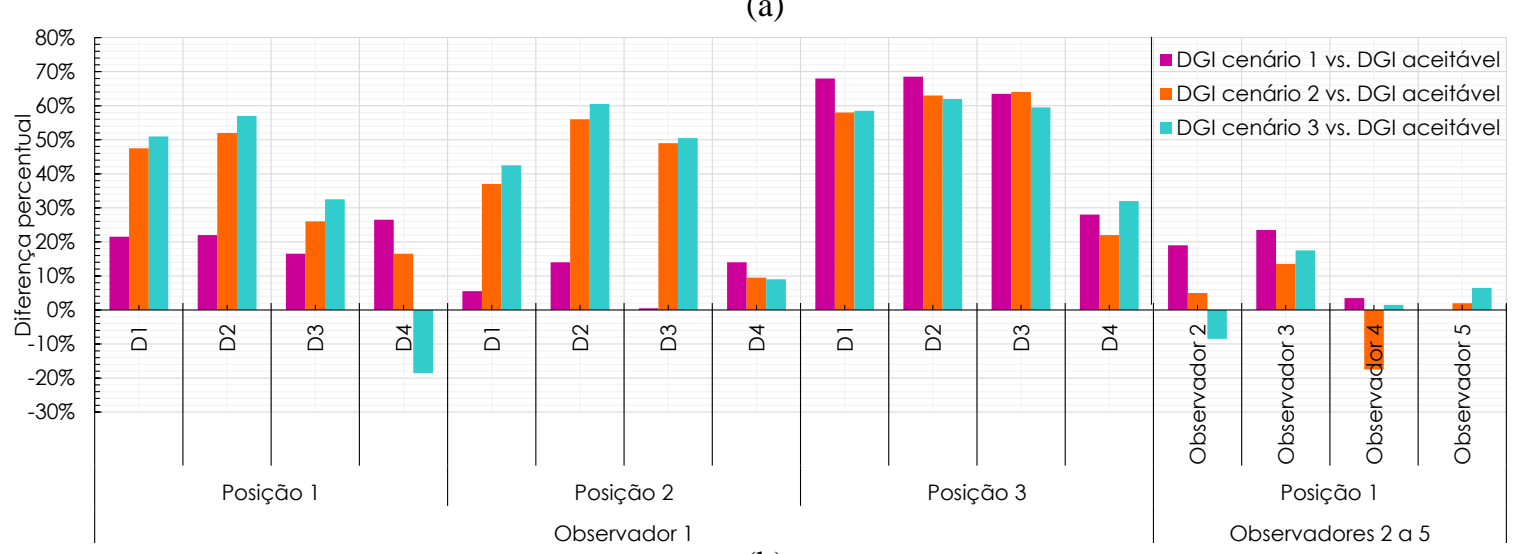

(b) 
Embora o DGI não seja o índice adequado para avaliar o ofuscamento por fontes pequenas, os valores obtidos na posição 3 evidenciam o impacto que a luz do projetor tem na avaliação do ofuscamento. Nesta posição os valores ultrapassaram a linha que define a sensação intolerável; com exceção da direção 4 , que sempre teve os menores valores em todas as posições, já que nesta direção não era enxergada nenhuma fonte de luz (janela ou projetor).

\section{Relação da avaliação do ofuscamento e o ambiente}

Com o intuito de identificar os valores do ofuscamento dentro do ambiente foram construídas imagens que permitissem dispor tais valores no espaço, considerando as variações estudadas e dessa forma reconhecer o impacto que poderia ter cada uma delas no cálculo do DGI.

A Figura 8 apresenta os resultados de DGI para as três posições do observador 1, para cada direção da visão e para os três cenários avaliados. As imagens apresentam a localização de todos os alunos que estiveram presentes na aula durante o período de gravação. Aqueles sujeitos marcados com cores indicam o foco da direção da visão a partir de cada uma das três posições identificadas. Os sujeitos na cor amarela representam o foco das direções da visão quando o observador 1 esteve localizado na posição 1; na cor verde as direções da visão quando o observador 1 esteve localizado na posição 2; e na cor roxa as direções da visão quando o observador 1 esteve localizado na posição 3. O sujeito marcado na cor azul indica o foco da direção da visão 1 a partir das três posições do observador. $\mathrm{O}$ valor do DGI da direção da visão 4 não é apresentado nas imagens devido ao fato de o foco da visão estar na tela de projeção.

Os três cenários e os valores de DGI para os observadores 2 a 5, que representam a localização de quatro alunos, e com foco de visão no centro da tela de projeção, são apresentados na Figura 9. Percebe-se que os valores de DGI para as direções de visão dos observadores 2,4 e 5 não sofreram grandes variações em cada cenário. Já o observador 3 (Ob3P1D1) apresentou os maiores valores de DGI em todos os cenários.

Devido ao fato de que o observador 1 foi quem apresentou maiores diferenças nos valores de DGI levantados foi realizada a comparação entre os três cenários, permitindo identificar a magnitude das mudanças do valor de DGI devido à configuração das cortinas. Os resultados são apresentados na Figura 10.

Figura 8 - Direções da visão a partir de cada posição do observador 1 e o respectivo valor de DGI
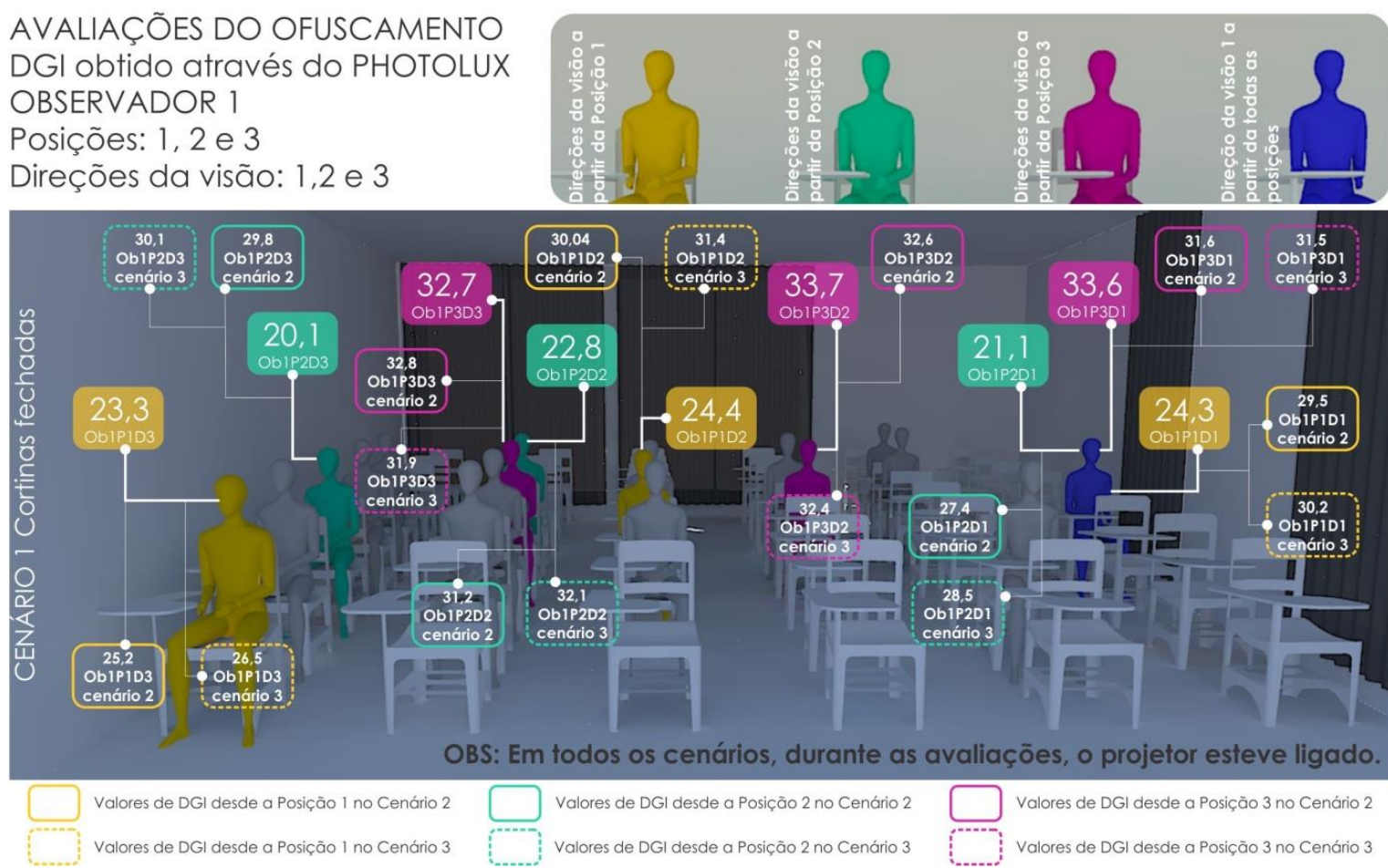

154 Vásquez, N. G.; Pereira, F. O. R.; Moraes, L. N.; Pires, M. O. 
Figura 9 - Posições dos observadores 2 a 5, direção da visão e respectivo valor de DGI

\author{
AVALIAÇÕES DO OFUSCAMENTO \\ DGI obtido através do PHOTOLUX \\ OBSERVADORES 2,3, 4 e 5 \\ Posição única \\ Direção da visão: centro da tela de projeções
}

OBS: Em todos os cenários, durante as avaliações, o projetor esteve ligado.
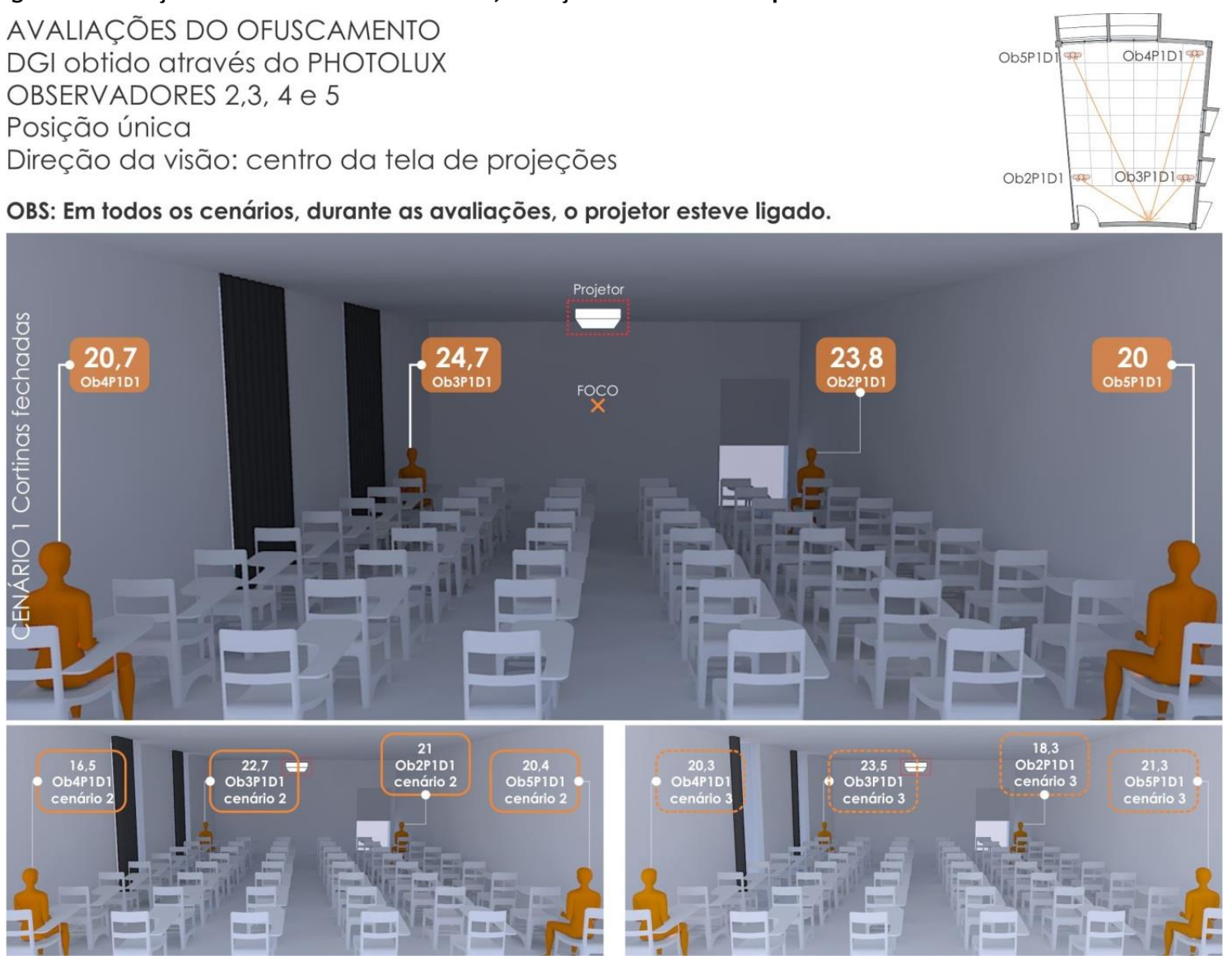

Figura 10 - Comparação das variações do DGI do observador 1 entre cenários

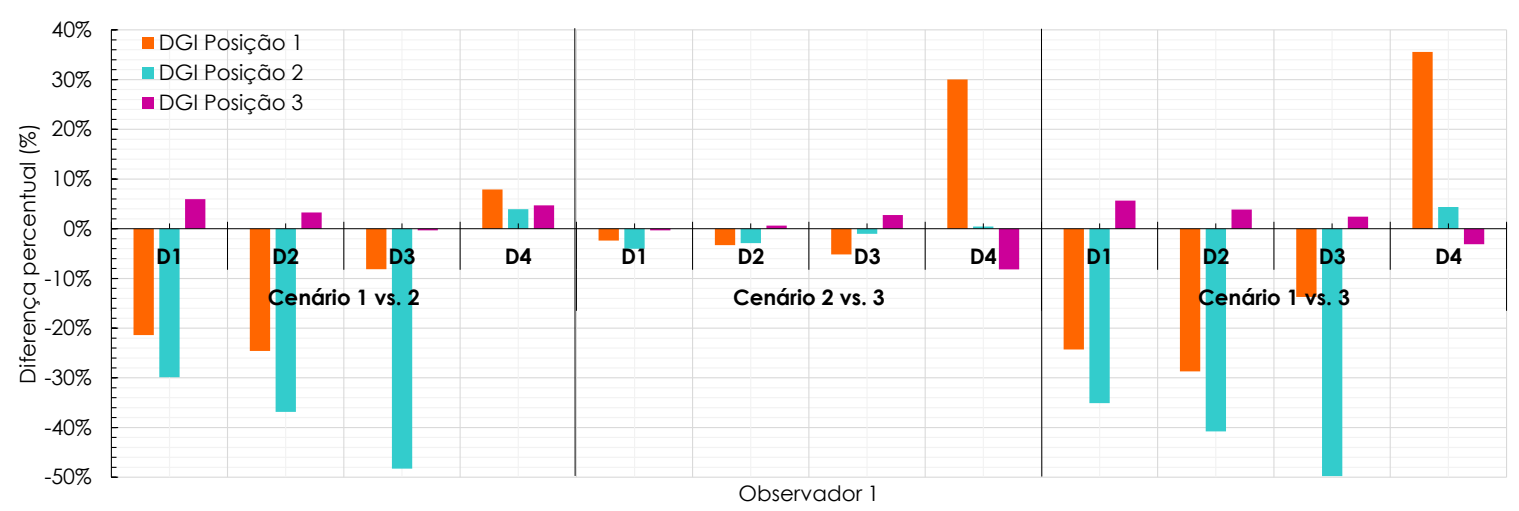

As diferenças entre os valores do DGI do cenário 1 vs. 2 e do cenário 1 vs. 3 nas posições 1 e 2 do observador 1 apresentaram as maiores variações (entre $-49,75 \%$ e $35,57 \% ; \quad \bar{X}=-19,35 \%$ ). Em ambas as comparações os valores de DGI obtidos quando as cortinas estiveram fechadas (cenário 1) foram os menores. A direção da visão D4 é a exceção dessa afirmação. Nessa direção, sob todos os cenários avaliados, o observador esteve de costas para as maiores fontes de luz natural, sendo percebido o brilho proveniente da parte inferior da porta e das superfícies iluminadas, sendo a pior condição a posição 1 , sob os cenários nos quais as cortinas estão parcialmente abertas e abertas. Essas variações oferecem uma ideia do impacto da posição das cortinas na avaliação do ofuscamento quando não há fontes pontuais de luz no campo de visão. Nessa situação o observador estava de costas para a luz do projetor.

Quando o observador esteve na posição 3 a amplitude das mudanças nos valores de DGI nos três cenários foi menor $(-8,20 \%$ até $5,95 \%)$. 
Contudo, a partir dessa posição foram levantados os maiores valores de DGI (Figura 6) devido a que a luz do projetor sempre esteve no campo visual.

No caso do cenário 2 vs. 3, com exceção da posição 1 na direção D4 (dif=30,04\%), foi possível identificar mudanças menores nos valores do DGI (entre $0,46 \%$ e $-8,20 \%$ ). Na posição 2 os índices encontrados foram muito parecidos, sendo a diferença máxima de $-4 \%$. Tirando a exceção da posição 1 , direção D4, a média da variação do DGI entre esses dois cenários foi de $|2,21 \%|$.

\section{Relação entre o DGI, o número de vezes em que cada direção foi olhada e o tempo}

Na Figura 11a são apresentados os valores de DGI versus o número de vezes que o observador olhou para cada uma das direções a partir das três posições. O número de vezes em que o observador olhou para cada direção está relacionado com o tempo de permanência em cada posição: na posição 1 todas as direções foram vistas mais vezes quando comparadas com os valores registrados na posição 3 .

A direção D4, que representa um ponto na parede de projeção, foi a mais vista a partir da posição $2 \mathrm{e}$ a segunda direção mais vista a partir da posição 1 . Essa situação pode ser explicada pela dinâmica própria da aula, já que em algumas ocasiões o professor fez explicações do conteúdo que estava sendo projetado. A partir da posição 3 essa direção foi a menos vista, embora o valor de DGI dessa direção tenha sido o menor obtido nessa posição. Com relação ao número de vezes em que o observador olhou para a direção D2, a partir da posição 1 , mesmo que o valor de DGI supere o limite "intolerável", esta foi a direção mais vista. Esse fato poderia ser explicado pelo possível interesse do observador nessa direção ou pelo melhor controle visual da sala e da informação projetada, evidenciando a influência das questões subjetivas na tolerância ao ofuscamento.

Na Figura 11b apresenta os valores de DGI versus a percentagem de tempo em que o observador olhou para cada direção em cada posição. Ao comparar as linhas plotadas nas Figura 11a e 11b é possível identificar a relação entre número de vezes e o tempo dedicado a olhar cada direção. A direção D1 foi aquela na qual o observador dedicou mais tempo nas três posições, embora não tenha sido a mais olhada a partir das posições $2 \mathrm{e}$ 3. Com os dados obtidos neste estudo não foi possível estabelecer uma relação entre os valores do índice DGI e o tempo que o observador olhou para cada direção. Esperava-se que essa relação fosse inversa, ou seja, quanto maior o valor do DGI, menor o tempo olhado nessa direção. Porém, isso não aconteceu em todas as situações. Essa análise destaca "o tempo" como mais uma variável importante que deveria ser considerada no estudo do ofuscamento.

\section{Influência do tempo na avaliação do ofuscamento}

A Figura 12 apresenta os valores de DGI obtidos diretamente do programa Photolux para cada posição e direção da visão $\left(D G I_{\text {Photolux }}\right)$, assim como os dados ponderados de direção pelo tempo $\left(D G I_{\mathrm{td}}\right)$. O DGI total da sala, considerando todas as posições, direções de visão e tempo em cada uma delas, está marcado na linha ciano.

Figura 11- (a) DGI de cada cenário vs. número de vezes em que o observador 1 olhou para cada direção; e (b) DGI de cada cenário vs. percentagem de tempo em que cada direção foi olhada pelo observador 1

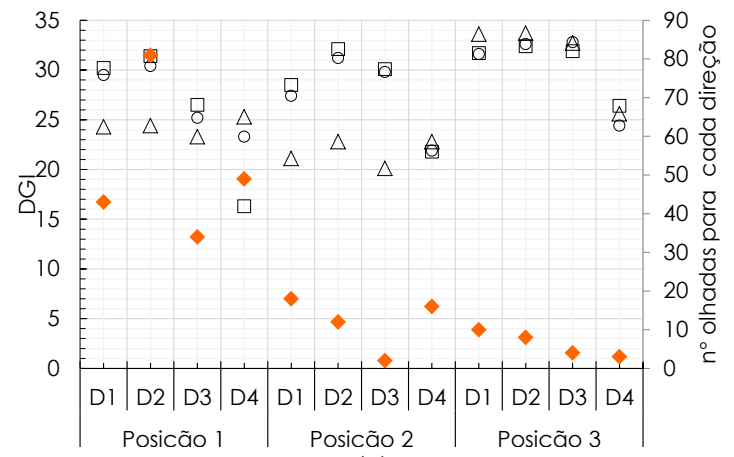

(a)

$\triangle D G \mid$ Cenário 1 घDGI Cenário 3

o DGI Cenário $2 * n^{\circ}$ de olhadas para cada direção

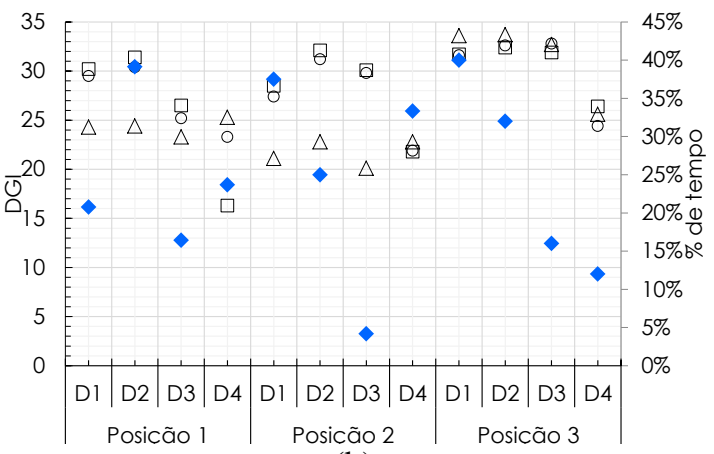

(b)

$\triangle \mathrm{DGI}$ Cenário $1 \quad \square \mathrm{DGI}$ Cenário 3

oDGI Cenário 2 \% Tempo 
A consideração do tempo no cálculo do DGI impactou positivamente nos resultados encontrados. Os valores de DGI total da sala encontrados foram, em quase todas as situações, inferiores aos valores de DGI de cada direção em todos os cenários. Sob as condições do cenário 10 DGI total da sala encontrado esteve entre os valores que definem uma sensação de ofuscamento “aceitável” e "desconfortável” (DGI total sala_cenário ${ }_{1}=23,37$ ). Para o cenário 2 o valor de DGI total da sala esteve acima do valor que define a sensação "desconfortável" (DGI total sala_cenário2 $=26,34)$. No cenário 3 o DGI total da sala apresentou valor inferior ao limite "desconfortável".

Cabe salientar que o interesse e a preferência visual não foram considerados neste estudo, no entanto relatos feitos pelo professor (observador 1) confirmaram o desconforto visual percebido na posição 3 devido à fonte luminosa do projetor. Observando-se a Tabela 3 verifica-se que nessa posição o indivíduo permaneceu por menos tempo.

A consideração do tempo de permanência em cada direção e da posição do indivíduo na proposição de um novo DGI retoma o conceito de adaptabilidade do indivíduo ante os estímulos visuais. Já que o contexto do campo visual proporciona momentos de desconforto e de descanso por determinados períodos, é possível encontrar um índice que reduza a avaliação da probabilidade de ofuscamento de determinada situação. A Figura 13 mostra as diferenças percentuais entre os índices pontuais obtidos no Photolux e os valores de DGI total da sala para cada direção a partir de cada posição.

O que pode ser observado são as reduções nos índices, comparados ao DGI total, através dos valores negativos do gráfico. O impacto que tem o tempo na avaliação do ofuscamento é claramente visível nos valores obtidos ao comparar o DGI do Photolux (pontos) com o valor do DGI ponderado pelo tempo (linhas horizontais). Na posição 3, com exceção da direção 4 no cenário 2 , todas as diferenças foram negativas, chegando a reduções de até $30,7 \%$ no valor do ofuscamento. Para o cenário 3, na posição 1 , percebe-se diferença positiva de $57,8 \%$, devido principalmente ao menor tempo de permanência do professor nessa posição.

Figura 12 - Comparação dos valores de DGI para o observador 1 em cada cenário

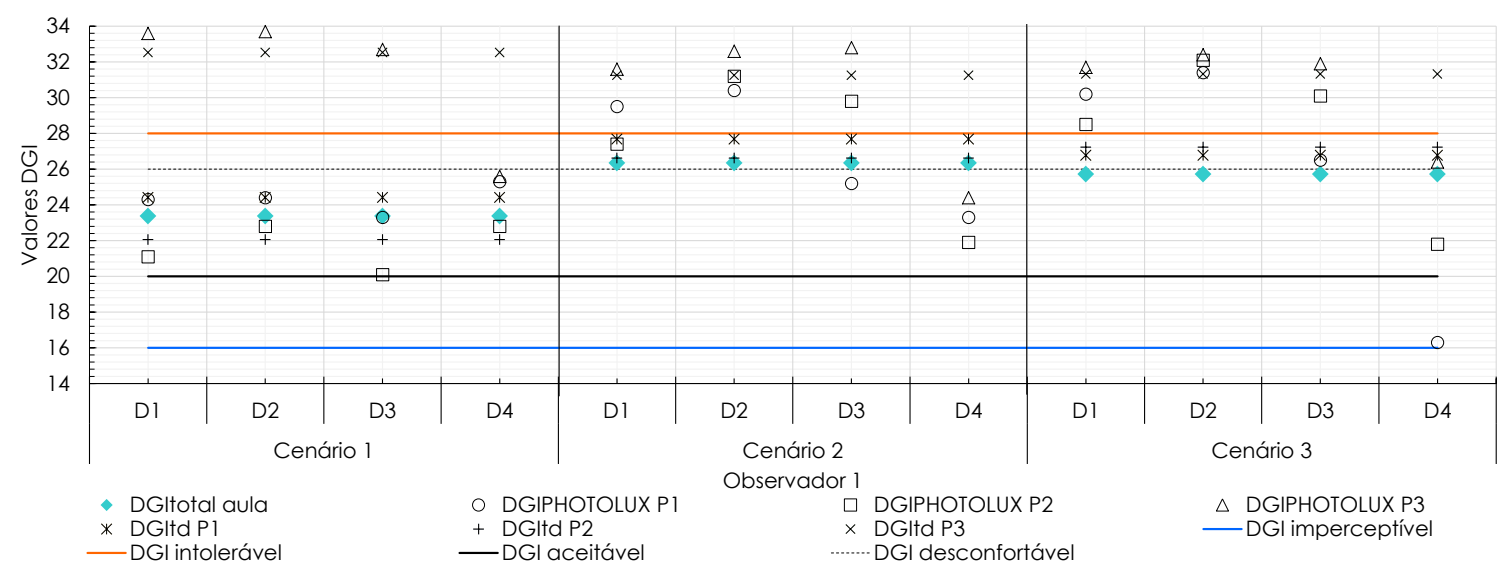

Figura 13 - Diferenças percentuais entre o DGItd e o DGI total da sala de aula do observador 1 para cada cenário - a sequência de dados para cada posição corresponde às direções da visão (D1, D2, D3 e D4)

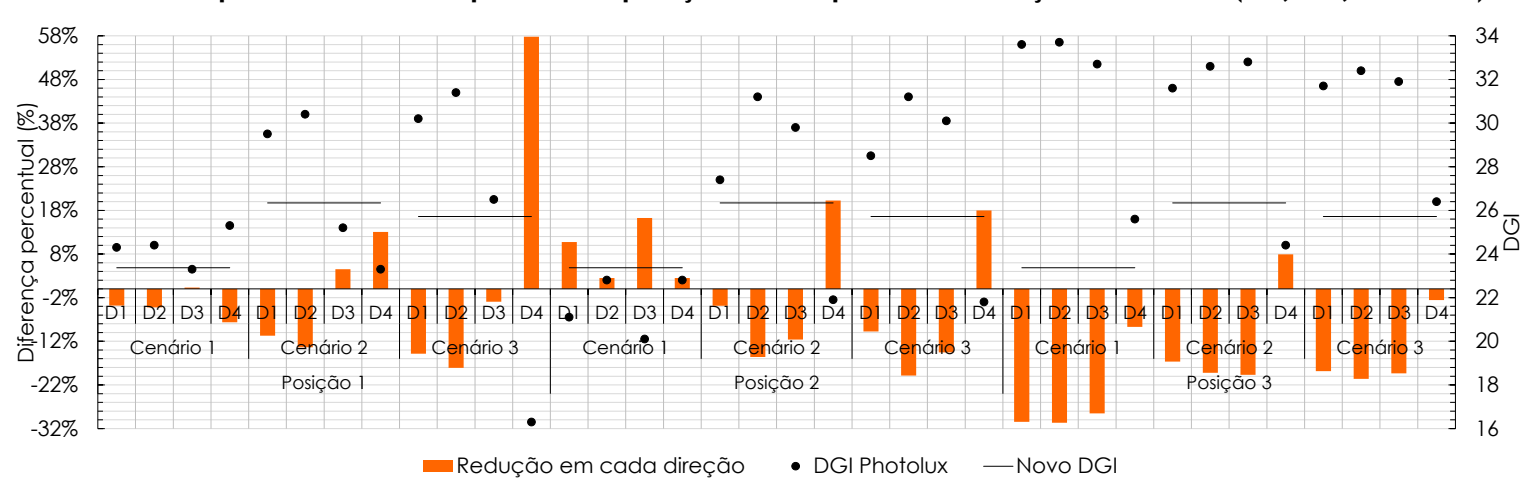


As comparações entre os valores pontuais de DGI encontrados por meio do método convencional de avaliação da probabilidade de ocorrência de ofuscamento (valores calculados pelo Photolux) e os novos valores obtidos, considerando-se um tempo determinado, são mostradas na Figura 14.

Além das informações quantitativas, as imagens permitem identificar a posição do observador dentro da sala de aula e o ângulo sólido definido pelas quatro direções da visão em cada uma dessas posições.

\section{Conclusões}

Neste trabalho foi realizada uma investigação acerca da influência da direção da visão e de diferentes condições de luminosidade dentro de uma sala de aula, a partir das posições predominantes de um professor e de quatro possíveis posições dos alunos. Os procedimentos adotados incluíram a utilização de filmagens, a aquisição de imagens HDR e o tratamento de dados através do programa Photolux.

Figura 14 - DGI total da sala de aula para o observador 1

\section{DGI TOTAL DA SALA DE AULA PARA CADA CENÁRIO| OBSERVADOR 1} POSIÇÃO 1
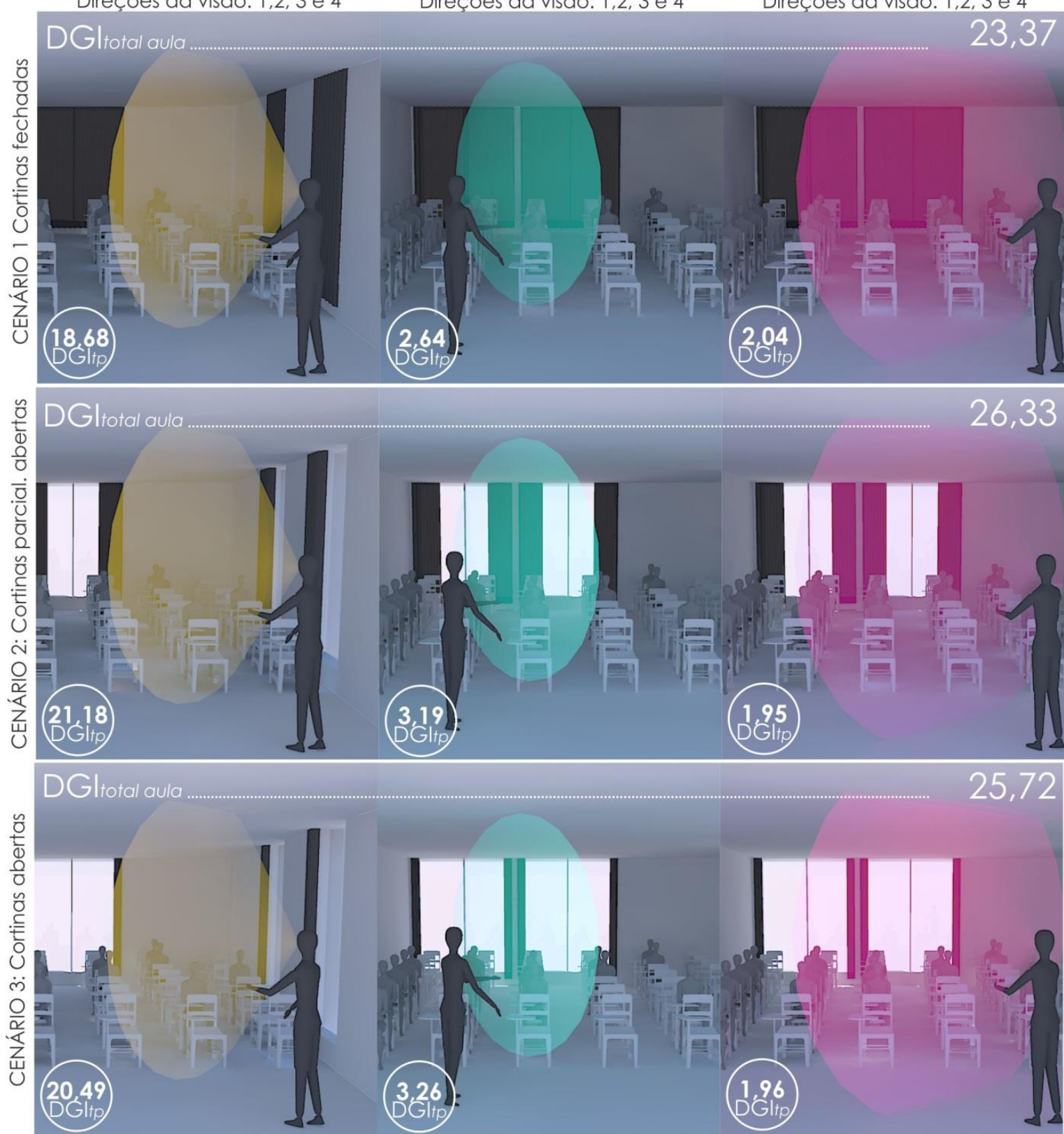

158 Vásquez, N. G.; Pereira, F. O. R.; Moraes, L. N.; Pires, M. O. 
Os resultados mostraram as ponderações do valor de DGI estático pelo tempo em cada posição, que derivaram em valores inferiores de $D G I_{\text {total }}$ da sala, para a maioria dos casos, o que representa uma redução na probabilidade de ocorrência de desconforto por ofuscamento. Considerando que uma das maiores limitações nas avaliações de presença de ofuscamento é a direção da visão, este estudo contribui na tentativa de se incorporar uma condição temporal às avaliações de direcionamento da visão.

Os resultados mostraram que a inclusão da variável tempo representa melhor o fenômeno do que a média dos valores de DGI para cada posição e direção de visão no interior da sala, podendo ser uma alternativa mais representativa de uma situação real dinâmica que o cálculo do DGI para uma única situação. Esses resultados aparentemente confirmam que o observador se beneficia da contínua variação do campo visual, alternando quando possível entre a visão de cenários mais ou menos estressantes. Contudo, neste estudo foi considerado o uso do projetor como uma prática comum nas salas de aula de educação superior, e os valores de DGI levantados através das imagens HDR e pelo uso do Photolux podem apresentar variações se comparados com uma situação na qual não seja usado o projetor. Devido a isso, é imprescindível replicar o experimento sob diferentes condições de iluminação, e assim identificar com exatidão os valores de DGI sobre os quais a ponderação pelo tempo poderia ser aplicada, de forma linear, como apresentado neste trabalho. Reconhece-se que existem outras variáveis que podem influenciar na sensação de ofuscamento além da duração e tempo de permanência, que podem ser avaliadas no campo da fisiologia do corpo humano, como o tempo de recuperação para adaptação do olho. Adicionalmente, a direção da visão (seja pelo número de vezes que uma direção é visualizada, seja pela duração) também é influenciada tanto pelo interesse visual como pela atividade visual do observador.

Foi encontrada uma relação entre o posicionamento do professor na sala e a perturbação oferecida pelo projetor na posição 3 , o que fez com que o tempo de permanência nessa posição fosse inferior aos demais. Porém, no decorrer do experimento foram observados alguns aspectos subjetivos relacionados ao posicionamento dos alunos em sala de aula, como a proximidade com a porta, para o caso de precisarem sair sem atrapalhar o andamento da aula, ou com as paredes, que servem como apoio. Essas constatações são importantes, uma vez que a complementação dos procedimentos adotados neste trabalho pode ser realizada através da aplicação de questionários com os usuários, para a identificação entre a percepção visual e os procedimentos propostos.

A partir desta experimentação, identificou-se que o uso da opção "Time Lapse” na gravação de vídeos facilita a identificação das estimativas de tempo para cada posição e direção da visão, promovendo maior precisão.

Os procedimentos propostos avançam na técnica de rastreamento da direção da visão utilizando procedimentos alternativos e mais acessíveis do que a tecnologia Eyetracking, mas ainda são necessários mais estudos para sua validação, já que os resultados encontrados corresponderam às condiçõos específicas deste estudo.

Quanto à configuração do ambiente, principalmente em relação à disposição das janelas, o estudo mostra que o espaço não proporciona o direito de escolha do indivíduo que está ministrando uma atividade em aula, a olhar para o exterior ou não, já que para as três posições estudadas, as mais recorrentes nesta atividade, todas as janelas do ambiente compõem o campo visual desse sujeito. Em outras palavras, para se direcionar aos alunos, as aberturas para o exterior sempre farão parte do campo de visão central e ergorama do observador, não havendo a opção de ele ter uma margem de descanso em caso de situações de ofuscamento desconfortáveis ou intoleráveis de brilho vindo do exterior. Sem dúvida, os padrões de uso das salas de aula dependem das atividades e das metodologias de ensino das instituições, idades dos alunos, conteúdo das disciplinas, etc. Da mesma forma em que avaliações subjetivas com os usuários ajudariam a aprimorar os resultados e conclusões com relação à percepção do ambiente visual, estudos sobre as características de uso e apropriação das salas de aula também são necessários para que arquitetos e engenheiros aprimorem os projetos de ambientes educativos. Como exemplo disso, além da adequada disposição e desenho das aberturas, a localização dos equipamentos de projeção (muito comuns na atualidade) influencia na percepção e sensação de conforto dos usuários.

\section{Referências}

ARIES, M. B. C.; AARTS, M. P. J.; VAN HOOF, J. Daylight and Health: a review of the evidence and consequences for the built environment.

Lighting Research and Technology, v. 47, n. 1, p. 6-27, 2015. 
BAKER, N.; STEEMERS, K. Daylight Desing of Buildings. London: James \& James, 2002.

BENFIELD, J. A. et al. Classrooms With Nature Views: evidence of differing student perceptions and behaviors. Environment and Behavior, v. 45, n. 4, p. 526-547, may 2013.

CAI, H. High dynamic Range Photogrammetry For Synchronous Luminance and Geometry Measurement. Lighting Research and Technology, v. 45 , n. 2, p. 230-257, abr. 2013.

CLEAR, R. D. Discomfort Glare: what do we actually know? Lighting Research and Technology, v. 45, n. 2, p. 141-158, abr. 2012.

DEBEVEC, P.; MALIK, J. Recovering High Dynamic Range Radiance Maps from Photographs. In: SIGGRAPH, Los Angeles, 1997. Proceedings... Los Angles, 1997.

HOPKINSON, R. G. Glare From Daylighting in Buildings. Applied Ergonomics, v. 3, n. 4, p. 206215, dez. 1972.

INANICI, M. N. Evaluation of High Dynamic Range Photography as a Luminance Data Acquisition System. Lighting Research and Technology, v. 2, n. 38, p. 123-136, 2006.

INANICI, M. N. Evalution of High Dynamic Range Image-Based Sky Models in Lighting Simulation. Journal of the Illuminating Engineering Society, v. 7, p. 69-84, dec. 2010.

INANICI, M. N. Evalution of High Dynamic Range Image-Based Sky Models in Lighting Simulation. Leukos, p. 37-41, dec. 2013.

JAKUBIEC, J. A.; REINHART, C. F. The "Adaptive Zone": a concept for assessing discomfort glare throughout daylit spaces.

Lighting Research and Technology, v. 44 , n. 2 , p. 149-170, jun. 2012.

JAKUBIEC, J. A.; REINHART, C. F. The "Adaptive Zone": a concept for assessing discomfort glare throughout daylit spaces. In: CONFERENCE OF INTERNATIONAL BUILDING PERFORMANCE SIMULATION ASSOCIATION, 12., Sydney, 2011. Proceedings... Sydney, 2011.

KENT, M. G. et al. Discomfort Glare and Time of Day. Lighting Research and Technology, v. 47, p. 641-657, ago. 2014.

KENT, M. G. et al.Temporal Variables and Personal Factors in Glare Sensation. Lighting Research and Technology, p. 1-22, mar. 2015.
KHANIE, S. et al. Investigation of Gaze Patterns in Daylit Workplaces: using eyetracking methods to objectify view direction as a function of lighting conditions. Paris: [s.n.], 2013a.

KHANIE, S. et al. Uncovering Relationships Between View Direction Patterns and Glare Perception in a Daylit Workspace. Krakow: [s.n.], 2013b.

KLEINDIENST, S. A.; ANDERSEN, M. The Adaptation of Daylight Glare Probability to Dynamic Metrics in a computacional Setting. In: LUX EUROPA: EUROPEAN LIGHTING CONFERENCE, 11., Istambul, 2009.

Proceedings... Istambul, 2009.

KULLER, R.; LINDSTEN, C. Health and Behavior of Children in Classroom With and Without Windows. Journal of Environmental Psychology, v. 12, p. 305-317, 1992.

PANERO, J.; ZELNIK, M. Las Dimensiones Humanas en los Espacios Interiores. Barcelona: Gustavo Gili, 2006.

REINHARD, E. et al. High Dynamic Range Imaging: acquisition, display and image-based lighting. San Francisco: Morgan Kaufmann, 2005.

STEWART, D. M. Attitudes of School Children to Daylight and Fenestration. Building and Environment, v. 16, n. 4, p. 267-277, 1981.

SUK, J.; SCHILER, M. Investigation of Evalglare Software, Daylight Glare Probability and High Dynamic Range Imaging For Daylight Glare Analysis. Lighting Research and Technology, v. 45 , n. 4 , p. 450-463, ago. 2013.

TUAYCHAROEN, N.; TREGENZA, P. Discomfort Glare From Interesting Images. Lighting Research and Technology, v. 37, n. 4, p. 329-341, Aug. 2005.

TUAYCHAROEN, N.; TREGENZA, P. View and Discomfort Glare from Windows. Lighting Research and Technology, v. 39, n. 2, p. 185200, 2007.

VAN DEN WYMELENBERG, K. G. Visual Comfort, Discomfort Glare, and Occupant Fenestration Control: developing a research agenda. Leukos, v. 10, n. 4, p. 207-221, 2014.

WIENOLD, J. Dynamic Daylight Glare Evaluation. In: IBUILDING CONFERENCE, Glasgow, 2009. Proceedings... Glasgow, 2009.

WIENOLD, J.; CHRISTOFFERSEN, J.

Evaluation Methods and Development of a New Glare Prediction Model for Daylight Environments With the Use of CCD Cameras. Energy and Buildings, v. 38, n. 7, p. 743-757, jul. 2006. 


\section{Agradecimentos}

Agradecemos ao $\mathrm{CNPq}$, pelo apoio financeiro (Processo: 475951/2013-1, Edital Universal 14/2013), e à Capes, pelas bolsas de pósgraduação.

\section{Natalia Giraldo Vásquez}

Laboratório de Conforto Ambiental, Departamento de Arquitetura | Universidade Federal de Santa Catarina | Campus Universitário | Florianópolis - SC - Brasil | Caixa Postal 476 | CEP 88040-900 | Tel.: (48) 3721-9393 | E-mail: ngiraldv@gmail.com

\section{Fernando Oscar Ruttkay Pereira}

Laboratório de Conforto Ambiental | Programa de Pós-Graduação em Arquitetura | Universidade Federal de Santa Catarina | Tel.: (48) 3721-7080 | E-mail: ruttkay.pereira@ufsc.br

Leticia Niero Moraes

Laboratório de Conforto Ambiental, Departamento de Arquitetura | Universidade Federal de Santa Catarina | in memoriam

\section{Maíra Oliveira Pires}

Departamento de Ciências Sociais Aplicadas | Universidade Regional Integrada do Alto Uruguai e das Missões | Rua Universidade das Missões, 464 | Santo Ângelo - RS - Brasil | CEP 98802-470 | Tel.: (55) 3313-7900 | E-mail: maira.opires@gmail.com

\section{Revista Ambiente Construído}

Associação Nacional de Tecnologia do Ambiente Construído

Av. Osvaldo Aranha, $99-3^{\circ}$ andar, Centro

Porto Alegre - RS - Brasil

CEP $90035-190$

Telefone: +55 (51) 3308-4084

Fax: +55 (51) 3308-4054

www.seer.ufrgs.br/ambienteconstruido

E-mail: ambienteconstruido@ufrgs.br 